\title{
An Knoblauchskröten experimentell entstandene überzählige Hintergliedmaßen.
}

\author{
Von \\ Gustar Tornier (Berlin). \\ Mit 46 Figuren im Text ${ }^{1}$. \\ Eingegangen am 9. Juli 1905.
}

\section{Einleitung und Methodik.}

Die vorliegende Arbeit enthält die Beschreibung der iiberzähligen Hintergliedmaßen von 12 Knoblauchskröten (Pelobates fuscus Laur.), welche alle nach ein und derselben Methode experimentell herrorgerufen worden sind. Die Operationsmethode war dabei folgende: Als bei jedem dieser Tiere im Larvenfrühstadium die beiden Hintergliedmaßenanlagen, selbständig voneinander und jede an einer der Körperseiten, als kleine Kegel mit kreisförmiger Umrandung (wie in Fig. 1 bei $b$ die rechte) gut erkennbar geworden waren, wurde versucht, an jedem Tier bei nur einmaliger Benutzung der Schere, und zwar durch einen einzigen Längsschnitt, die beiden Gliedmaßenanlagen in ihrem oberen Teil gleichzeitig und gleichartig zu durchschneiden.

Diese Versuche waren, wenn auch schwierig, doch ausführbar, da diese Gliedmaßenanlagen vom Schwanze der Larve her leicht zugänglich sind, ferner - wie bekannt - in gleicher Höhe des Tier-

1) Die dieser Arbeit beigegebenen Abbildnngen nud sonstigen Zeichnungen sind von Herrn Kunstmaler Parl Flanderky (Berlin) angefertigt, es mag auf deren große Naturtreue noch ausdrïcklich lingewiesen werden. Über die in dieser Abhandlung ausführlich besprochenen Tiere aber wurde bereits in der Gesellschaft naturforschender Freunde zu Berlin ganz kurz berichtet (Sitzungsber. d. Ges. 1904. S. 166), desgleichen auf dem internationalen Zoologenkongreß in Bern 1904 (Compte-Rendu des Séances du Congrès international de Zoologie. 1905. p. 327). An beiden Orten wurden die Tiere auch vorgezeigt. 
körpers einander genau gegenüber liegen und dabei durch nur wenig Körpersubstanz voneinander getrennt werden; die Methode versah denn auch die Operationstiere, wie von vornherein beabsichtigt war, einmal mit iiberzähligen Gliedmaßen und ergab bei einigen zweitens auch noch die ebenfalls gewünschte gleichsinnige Verbildung ihrer beiden Körperseiten durch einen einzigen Scherenschnitt, d. h. durch einen einzigen Angriff von außen.

Wer da aber glaubt, diese Operationsmethode wäre leicht zu finden gewesen, der irrt doch sehr. Es wurden sehr viele Versuche ohne Erfolg angestellt, bis dieser letzte endlich die gewtinschten Resultate herbeifuihrte. Der Grund fiur das Fehlsehlagen der Vorversuche aber ist folgender:

Durch Studium an Fröschen, welche in der freien Natur Hintergliedmaßen in Überzahl erlangt hatten, war von mir schon vor Anstellung von Versuchen festgestellt worden, daß Fig. 1. bei all jenen Naturobjekten die Zersprengung einer Beckenanlage zur Entstehungsursache fiur iiberzählige Gliedmaßen geworden war. Da nun bei er-

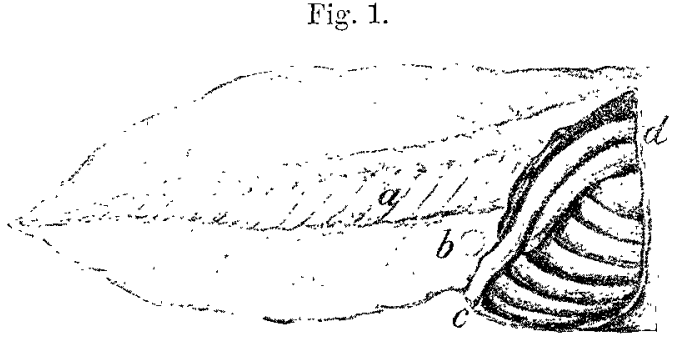
wachsenen Fröschen jede Hintergliedmaße einer zugehörigen Beckenhälfte (Fig. $4 a-c$ ) ansitzt, deren Körper $(a)$ für sie eine Gelenkpfanne $(b)$ trägt, und ferner mit einem langen schmalen Darmbeinflitgel $(c)$ zum Kreuzbeinfortsatz (d) illrer Körperseite hinzieht, so nahm ich an, daß auch schon in dem indifferenten Gewebe der Larve - also in Fig. 1 zwischen $b$ und einem Punkt der Schwanzmuskulatur $(a)$ - von jeder Hintergliedmaßenanlage zur Kreuzbeinanlage eine - allerdings morphologisch nicht sichtbare - Darmbeinflügelanlage hinüberziehe und so hoffte ich, diese Darmbeinfliigelanlage der Larve zu durchschneiden und dadurch experimentell überzählige Hintergliedmaßen hervorzurufen, indem ich bei der Larve die Leibeswand zwischen der Wirbelsäule und einer Hintergliedmaßenanlage durchschnitt (in Fig. 1 also zwischen $a$ und $b$; aber diese Methode ergab, so sebr oft sie wiederholt wurde, nicht das Gewünschte, sondern die auf diese Weise erzengten Wunden, welche oft sehr umfangreich waren, verheilten stets ohne jede Komplikation. Erst als daun in die kreisförmigen Hinter- 
gliedmaßenanlagen der Larven unmittelbar eingeschnitten wurde, war die erfolgreiche Operationsmethode gefunden und damit zugleich für mich der erste Beweis đafür, daß bei den Fröschen die Darmbeinfligelausbildung in andrer Weise zustande kommt, als ich vermutet hatte. Direkte Präparation hat es dann zum zweiten Male bestätigt, indem sie folgendes ergab:

Bei erwachsenen Knoblauchskröten besteht das Becken (Fig. 4) aus zwei spiegelbildlich gleichen Hälften, die in ihren keilförmig verdickten Hinterenden miteinander untrennbar verwachsen sind, während das stielartig verlängerte Vorderende jeder Beckenhälfte an dem zugehörigen Kreuzbeinwirbelfortsatz gelenkt. Das keulenartig verdickte Hinterende jeder Beckenhälfte, welches je nach seiner Lage als rechter $(a)$ oder linker Beckenkürper bezeichnet werden kann, besteht dabei aus zwei nebeneinander liegenden Knochen, dem Darmund Sitzbein (1 und 2), die in einer senkrecht stehenden Naht anein-

Fig. 2.

Fig. 3.
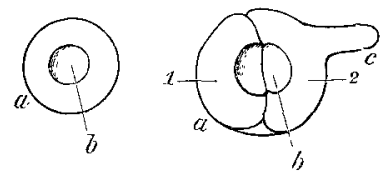
ander stoßen und gemeinsam an ihrer Außenseite die Pfanne (b) für die zugehörige Hintergliedmaße tragen. Der Stiel jeder Beckenhälfte $(c$ wie auch $c^{\prime}$ ) erweist sich alsdann als ailciniger Fortsatz eines Darmbeinknochens $(-2)$, also als Darmbeinflügel. - Sehr wichtig fïr diese Untersuchungen ist dam anßerdem, daß beim erwachsenen Frosch der Enddarm zwischen den beiden Darmbeinfligeln hindurch und ïber den Darmbeinkörpern entlang zieht und in den After endet, der ebenfalls iiber den Darmbeinkörpern liegt.

Die ontogenetische Entwicklung dieses Beckens mit seinen Darmbeinflïgelu und zwei Gliedmaßen aber ist nun folgende:

Die beiden Beckenhälften beginnen ihre Entwicklung völlig unabhängig voneinander und weit roneinander getrennt, denn was in dieser Arbeit bisher einfach als eine Gliedmaßenaulage cines Frosches bezeichnet wurde (Fig. 1 in $b$ ist die rechtsseitige), enthält in Wirklichkeit die Keimsubstanzen für eine ganze Beckenhälfte des Tieres mitsamt der dazu gehörigen Gliedmaße und ist dabei als kleiner scheibenförmiger Zellhaufen bei ihrem ersten Auftreten und auch in ihrem ganzen späteren Entwicklungsverlauf geradezu das Muster eines "Keimbezirks im HIs-Rouxschen Sim, den ich als Beckenbezirksanlage bezeichnen will. Sie liegt ferner, wie schon angegeben wurde (Fig. 1 in $b$ ), an einer der Körperseiten des Tieres 
und zwar zwischen After (c) und Schwanzwirbelsäule (a), von diesen beiden etwa gleich weit entfernt. Ans diesem im Anfang kugligen Zellhaufen sondert sich nun bei der Entwicklung zuerst (Fig. 2) die Uranlage der darin enthaltenen Beckenhälfte als eine richtige kreisrunde Knochenscheibe ab, auf deren Außenseite (in der Gelenkfläche b) sich die zugehörige Gliedmaße aufbaut. Es wird also von der Beckenhälfte zuerst der Körper ausgebildet, nicht dagegen der zugehörige Darmbeinflïgel. Anßerdem aber ist sehr charakteristisch, daß in dieser ontogenetischen Entwicklnngsperiode des Tieres, wie schon erwähnt, der After unter den Beckenbezirksanlagen liegt und der Enddarm vom After aus vor ihmen schräg nach oben hin aufsteigt. Das kommt aber daher, weil bei der Froschlarve - im Gegensatz zum erwachsenen Tier - ein Seluwanz vorhanden ist, der seitlich zusammengedrïckt ist und an seiner Ober- und Unterseite von breitem Hautsanm umgeben wird, an dessen Unterkante dann der After mïndet, und daß ferner die Leibesböhle der pflanzenfressenden Larve viel umfangreicher ist als die des Fig. 4.

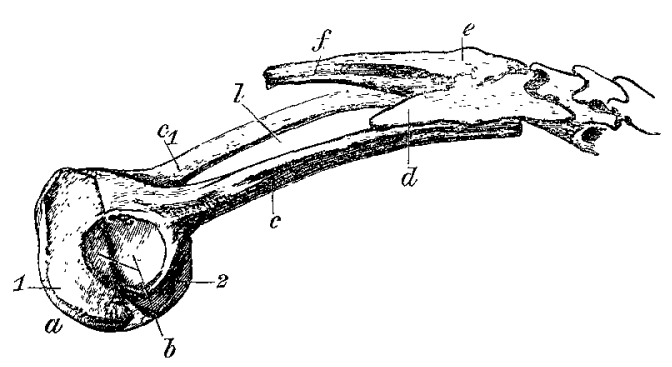
insektenfressenden erwachsenen Tieres. Später nun (Fig. 3), wenn aus der Beckenbezirksanlage nach dem Beckenkörper $(\alpha)$ die Hintergliedmaße zur Entwicklung kommt, entsteht aus dem bis dahin allein vorhandenen Beckenkörper (a) als richtiger Answuchs des Darmbeins gleichzeitig auch der Darmbeinflugel (c) und verlïngert sich relativ langsam bis zum Kreuzbeintlügel (Fig. 4: d).

Noch später, wenn die Hintergliedmaßen des Tieres eine bestimnte Größe erlangt haben, beginnt am Larvenschwanz der Saum langsam zu schrumpfen und gleichzeitig nimmt die Leibeshöhle des Tieres an Höhe und Breite $a b$, infolgedessen wandert dann der Enddarm der Wirbelsäule des Tieres zu, zwischen den noch völlig getrennten Beckenlälften hindurch. Kaum aber ist der Enddarm mit seiner oberen Hälfte über die obere Kante des Beckenkörpers hinausgelangt, so legen sich diese bereits mit ihren nuteren Kanten aneinander. Es bildet sich dann in dem Enddarm des Tieres un- 
mittelbar über und hinter den Beckenkörperhälften ein zweiter, also nener, After aus, während der alte mit dem Sehwanzsaum des Tieres, zu dem er ja gehört, aufgesaugt wird. Jede Knoblauchskröte hat also einen "Larvenafter und einen davon völlig verschiedenen und viel später entstehenden »Dauerafter *; Verhältnisse, anf die ich aber nicht weiter in dieser Arbeit eingehen will.

\section{Abschnitt I: Die Formcharaktere der Regenerate.}

Durch die in der Einleitung zu dieser Arbeit angegebene Versuchsanstellung sollte bei jedem Tier an jeder seiner beiden Beckenbezirksanlagen die obere Kappe durch gemeinsamen Scherenschnitt losgelöst, d. h. es sollte dabei in Wirklichkeit (wie das Fig. 5 zeigt) die darin enthaltene Anlage einer Beckenbälfte $(g . h)$ im oberen Teil lïngs durchschnitten werden (im Verlauf der Punktlinie $s-s$ ) und sollten dabei gleichzeitig, wenn möglich, beide Beckenhïlften des Tieres möglichst gleichartig durchschnitten werden; infolgedessen trugen - weil in gleicher Methode behandelt - all diese Tiere fast oder ganz gleichartige Beckenwunden davon und erhielten aus diesen dann natïlich auch mehr oder weniger gleichartige Regeneralanlagen mit der naclffolgenden Entwicklungstendeuz:

Die abgeschnittene obere Kappe $(h)$ jeder derartig durchschnittenen Beckenanlage (Fig. 5, 6 und 7) hat stets das Bestreben, aus ihrer Wundflache $(s s)$ ein ganzes iiberzïlliges Becken mit zugehörigen zwei Hintergliedmaßen regenerell ${ }^{1}$ ) auszubilden, wobei die itberzähligen Gliedmaßen das Bestreben haben, voneinander frei zu bleiben, aber ein normgleiches Symmetrieverhältnis miteinander einzugehen, d. h. sie werden die rechte und linke Hintergliedmaße zu dem iiberzähligen Becken, an dem sie sitzen. Der untere Beckenahschnitt dagegen (Fig. 5, 6, 7:g) erzengt aus seiner Wundfläche stets nur den ihm verloren gegangenen Beckenabschnitt $\left(h^{\prime}=h\right)$ wieder, d. h. eine

1) Statt des von Merrn Prof. BARFurer vorgeschlagenen langen nud im Dentschen schwer zu behandeInden Wortes "regenerativ werden in dieser Abhandlung, vielleicht zum ersten Mal, das kuirzere sregenerell und als Vorsatzwort "regeneral-« gebrancht, die entsprechend den vielen lateinischen Adjektiven auf alis (oder des Wohlklangs wegen auch aris) gebildet sind. Beispiele sind: experimentare, experimentell (in Rïcksicht auf oder durch das Experiment) und experimental (-Versuch; ; medicinare, medicinell und medicinal (-Person); nominare, nominell, nominal (-Betrag); notare, notariell, notarial (-Vertrag); formare, formell, formal; titulare, titnlar-, titulitr usw. Regenerar- und regenerarisch lassen sich der Lünge und des Wohlklangs wegen nicht anwenden. 
neue Kappe, welche dann erst später aus sich heraus den zugehörigen einfachen Darmbeinflïgel $(c)$ zur Entwicklung bringt. Wurden also bei einer so operierten Larve die beiden Beckenhälftenanlagen ganz gleichwertig verwundet, wie bei der in Fig. 8 abgebildeten, wo $m-m$ die Mittellinie des Tieres angibt, so traten bei ihr an beiden Körperseiten ganz gleiche Regeneraltendenzen auf und so erhielt das Tier auch, wenn keine nachfolgenden Entwicklungshemmungen dazwischentraten (wie das eben Fig. 8 und 22, 23 zeigen), auf beiden Körperseiten ganz gleichartige überzählige und regenerell ergänzte Gebilde, und zwar, wie schon angegeben, mit je einer normal gestalteten und als »normale« zu bezeichnenden Beckenhälfte (Fig. 8: $\left.g, h^{\prime}, c\right)$, deren oberer Teil $\left(h^{\prime}, c\right)$ regenerell ergünzt ist, und je ein

Fig. 5. Fig. $6 . \quad$ Fig. 7.
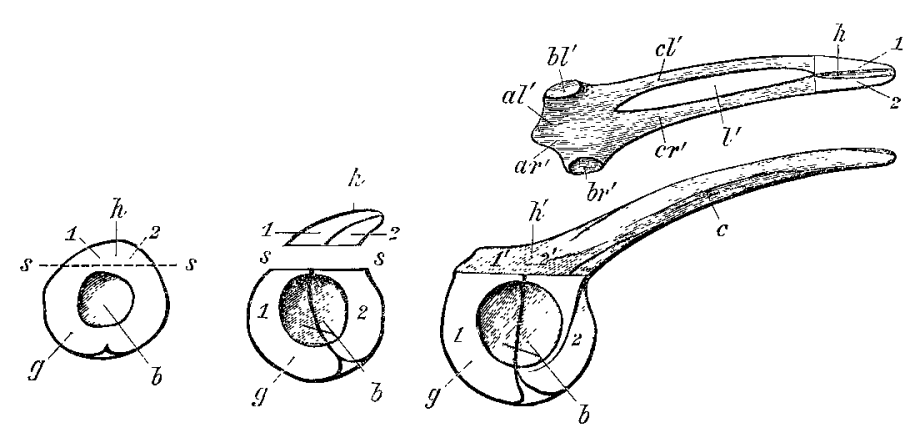

überzähliges Becken $\left(h-a^{\prime}\right.$ ) mit zugehörigen zwei Gliedmaßen, die als ïberzählige in den zwei Gelenkpfannen $b^{\prime}$ dem überzähligen Becken ansitzen. Im ganzen also erhielt das Tier auf diese Weise sechs Hintergliedmaßen.

Der untere Abschnitt $(g)$ jeder Beckenhälfte wahrte also bei seinem Regeneralverlauf streng seine Beziehungen zur Körperpolarität, d. h. er erzengte genau das als neu, was ihm vorher verloren gegangen war. Das Regeneralverhalten des oberen Abschnitts der betreffenden Beckenhälfte $(h)$ dagegen entspricht keineswegs der Körperpolarität des Tieres und ist folgendes: Da zur Zeit, in welcher von der Anlage der betreffenden Beckenhälfte dieser obere Kappenabschnitt (h) losgetrennt wurde, an der Beckenhälfte selbst ein Darmbeinflügel $(c)$ noch nicht vorhanden war, so bestand der losgelöste obere Kappenabschnitt $(h)$ der Beckenhälfte aus der Spitze einer Beckenkörperhälfte, mithin aus zwei Knorpelkernen, einem Sitz- und Darmbein- 
stück (Fig. $6 h: 1$ und 2), die nebeneinander lagen. Es regenerierte dann von diesen beiden Skelettstiucken jedes eine ïberzählige Beckenhälfte (mit zugehöriger Gliedmaße), die beide schon bei ihrem ersten Entstehen miteinander in Berührung kamen und sich deshalb - in Bestätigung des von mir gefundenen Symmetriegesetzes - symmetrisch zueinander anlegten und so zu einem normal gestalteten überzähligen Becken mit zugehörigen zwei Gliedmaßen wurden.

Wenn nun also auch diese Knochenstiicke (1 und 2) des oberen Abschnitts $(h)$ einer Beckenhälfte, jedes für sich, nur einen halben

Fig. 8.

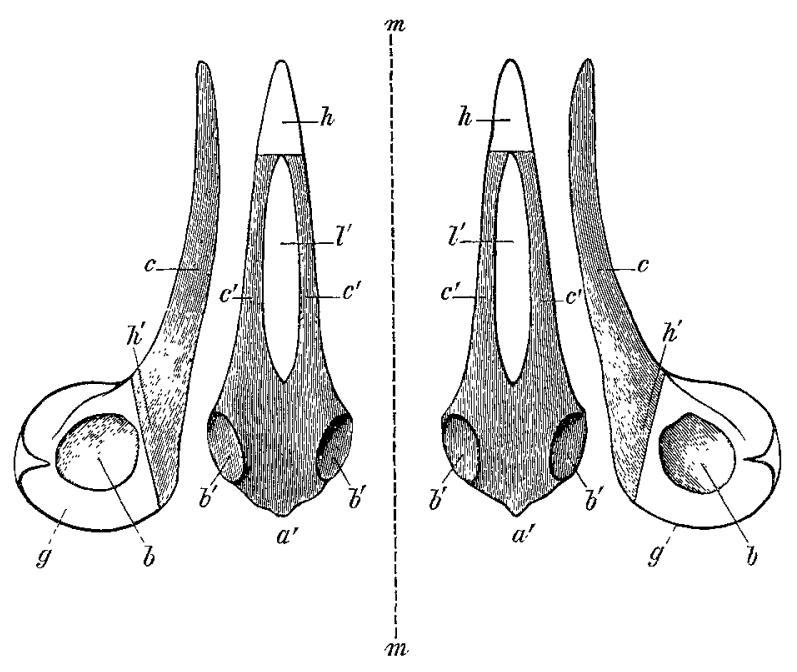

überzäbligen Beckenbezirk erzeugten, so können doch nur ganz oberflächliche Betrachter annehmen, daß diese Knochenstücke bei ihrer Regeneration polar vorgegangen sind. Es wäre wirklich geschehen, wenn sich z. B. die Sitzbeinkerne etwa wie in Fig. 10 verhalten hätten, wo das Stuick 1 eine derartige zur Regeneration bestimmte rechtsseitige Sitzbeinkappe bezeichnet und das Übrige der Figur eine streng polar aus ihr regenerierte Beckenhälfte. In Wirklichkeit aber schließt sich bei allen mir vorliegenden Objekten (wie in Fig. 9) an ein derartiges Sitzbeinstiick (1) numittelbar der aus ihm regenerierte Darmbeinflügel $\left(c^{\prime}\right)$ an und in dem daran hängenden Beckenkörper ist das Sitzbeinstiick 1, das die Regeneration einleitete, in $1+$ regenerell verdoppelt enthalten; $d$. h. also: es hat seinesgleichen regenerell noch einmal erzeugt. Es stellt also in diesem Fall das regenerierende 
Sitzbeinstück (1) funktionell eine Darmbeinflügelspitze ( $c^{\prime}$-Spitze) dar, ja es wird bei den vorliegenden Objekten von seinem eignen Regenerat geradezu als eine solche benutzt, indem es durch dieses Regenerat, wie noch väher ansgeführt werden soll, zum Schluß gegen den Kreuzbeinfligel seiner Körperseite hin transportiert wird und sich dann daselbst genau so anlegt, wie eine richtige Darmbeinflïgelspitze.

In Riicksicht auf das eben Gesagte könnte nun für Regeneralvorgänge wie in Fig. 7, wo aus einem oberen Beckenkörperabschnitt $(h)$ ein ganzes iiberzäbliges Becken so herausgewachsen ist, daß sich an den regenerationauslösenden echten Beckenkörperabschnitt $(h)$ die iiberzähligen Darmbeinflügel $\left(c^{\prime}\right)$ unmittelbar anschließen, angenommen werden: es sei bei derartigen Regenerationen der betreffende regenerierendo echte Beckenkörperabschnitt $(h)$ wirklich zuletzt zur Spitze der aus ihm entstandenen überzällligen Darmbeinflitgel $\left(c^{\prime}\right)$ sumdifferenziert« worden; ich bin aber aus den Befunden an andern Objekten durchaus nicht dieser Ansicht, sondern der Fig. 9. Fig. 10.

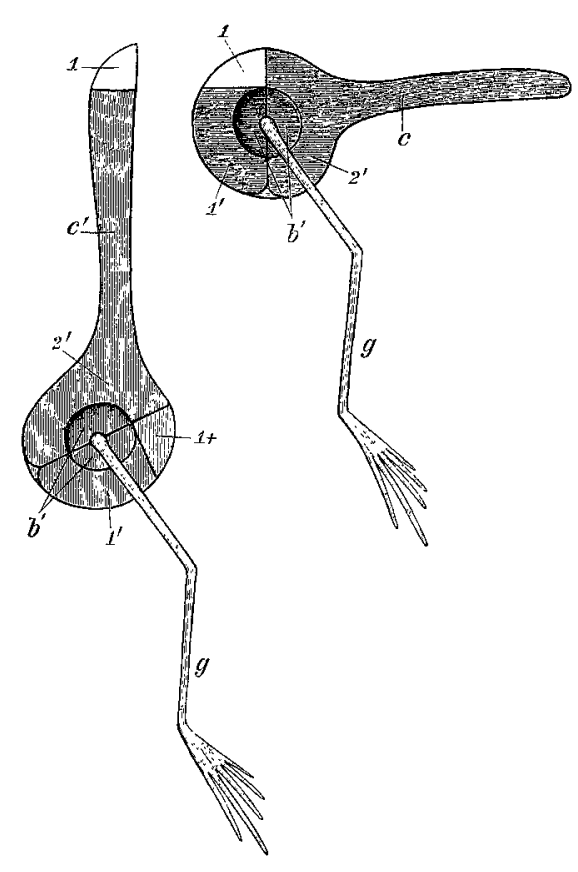
entgegengesetzten, da $\beta$ in all diesen Fällen das regenerierende echte Beckenkörperstück stets seinen ursprïnglichen Charakter unverändert beibehält und nur funktionell eine Darmbeinfliggelspitze zu ersetzen gezwungen wird. Auf das apolare Verhalten in diesem Regeneralverlauf aber will ich hier nun nicht noch weiter eingehen, da ich es an andrer Stelle mit noch andern Beispielen ausfibrlich zu besprechen gedenke. -

An den vorliegenden verbildeten Fröschen fallen dann, wie die Vollbilder und Beckenabbildungen der Tiere in Abschnitt III dieser Arbeit ohne Schwierigkeit erkennen lassen, noch folgende morpho- 
logische Charaktere anf, deren Entstehungsweise im nächsten Kapitel dieser Arbeit aufgedeckt werden soll:

Das ubberzählige Becken ist erstens stets kleiner als das echte Becken des Tieres, zu dem es gehört. Es liegt zweitens gewöhnlich mit der Längsachse wie ein echtes (nur ein einziges der untersuchten weicht von dieser Regel ab).

Das iiberzählige Becken liegt drittens mit seinem Körper entweder vor oder auf oder hinter der echten Beckenhälfte, zu der es gehört, wie das Fig. 17-20 zeigen, wobei dann anch die überzähligen Gliedmaßen entweder vor der zugehörigen Stammgliedmaße liegen, oder auf oder hinter ihr.

Es liegt viertens das überzählige Becken entweder höher als die zugehörige Stammbeckenhälfte oder darauf oder tiefer als sie, wobei dann auch die überzähligen Gliedmaßen entweder höber als die zngehörige echte liegen oder darauf oder tiefer als sie.

Das ïberzählige Becken liegt fünftens mit seiner Querachse entweder wie das echte, d. h. mit ihr horizontal (Fig. 17 und 18), oder mit derselben mehr oder weniger senkrecht (Fig. 19). Es hat sich dann also aus der Normalstellung nach außen herum bis zu einem Winkel weit uiber 90 Grad gedreht (in Fig. 20 sogar um 180 Grad), woraus folgt, daß die zugehörigen Gliedmaßen dann ihre Bauch seite entweder wie echte nach unten richten, oder aber nach außen, oder sogar mehr oder weniger nach oben.

Es sind sechstens das ỉberzählige und Stammbecken entweder ganz unabhängig voneinander oder mehr oder weniger miteinander verwachsen.

Das Überzählige jeder Körperseite ist siebentens nur zuweilen ganz seiner Regeneraltendenz entsprechend ansgebildet, besteht dann also aus einem ganzen iiberzähligen Becken mit zwei zugehörigen Gliedmaßen; bei andern Tieren zeigt dagegen das Überzählige einer oder beider Körperseiten starke Entwicklnngshemmungen oder Fehlstellen: so kann an ihm z. B. eine ganze Hälfte fehlen oder nur in Rudimenten vorhanden sein. Es können an den überzähligen Gliedmaßen und an der mit ihnen verwachsenen echten einzelne Finger oder selbst die Fỉße bis auf Reste fehlen und es fehlen zuweilen im Innern der ïberzähligen Gliedmaßen der Oberschenkelknochen, und zuweilen anßerdem auch noch die beiden Unterschenkelknochen, oder all diese Knochen sind mehr oder weniger verbildet.

öfter sind auch die überzähligen Gliedmaßen von der Wurzel an miteinander verwachsen. Derartige Doppelgliedmaßen haben dann 
in der Mitte des zugehörigen Doppelfußes zwei selbständig aneinander liegende oder miteinander verwachsene Fußschaufeln, (oder innere Metatarsalhöcker, wie der herpetologische Fachausdruck lautet) (Fig. 34 in s). In andern Fällen ist eine überzählige Hintergliedmaße mit der zugehörigen echten verwachsen und derartige Doppelfüße haben dann an jedem ihrer zwei Außenränder eine Schaufel (Fig. 29 in $s)$.

\section{Abschnitt II: Entstehungsursachen der einzelnen Regeneratformen.}

In diesem Abschnitt der vorliegenden Abhandlung sollen die Entstehungsursachen der soeben an den Objekten und ihren Regeneraten nachgewiesenen Formcharaktere klargelegt werden und ist deshalb zuerst die Frage za lösen: Warum ist das uiberzählige Becken stets kleiner als ein echtes? Da scheint mir nun für das Wachsen des überzähligen Beckens ein Gesetz bestimmend zu sein, das freilich noch sehr der Nachprüfung bedarf und folgendermaßen lautet: Die Massengröße des aus einem oberen Beckenkörperabschnitt voll erwachsenen Regenerats ist direkt proportional der Massengröße jenes Abschnitts und in letzter Instanz direkt proportional der Flächengröße der Wundfäche, die an jenem Abschnitt vorhanden ist. Auch dürfte dieser Satz sehr wahrscheinlich als allgemeines Regeneralgesetz in folgender Fassung Geltung haben: Die Massengröße eines Regenerats, wenn es nicht sekundär in der Ausbildung gehemmt wird, ist direkt proportional der Flächengröße der Wundfläche, aus welcher es entsteht.

Dieses Gesetz wird durch folgende Überlegung sehr wesentlich gestiitzt: Wird bei zahlreichen Individuen derselben tierischen Art (also z. B. von Triton eristatus), die aber sehr verschiedenes Alter haben, ein und dieselbe Gliedmaße immer an genau derselben Stelle abgeschnitten, so erhält diese Gliedmaße stets die zu dem Gesamtkörper des Tieres passende Größe, wird also klein bei kleinen Tieren, groß bei großen; und da nun bei all diesen Tieren die Regeneralflächen qualitativ gleichwertig sind, kann also nur die Größe derselben für die Massenentwicklung des Regenerats ausschlaggebend sein.

Dagegen ist mir bisher nicht möglich gewesen, herauszubringen, warum normalerweise jedes überü̈hlige Becken mit seiner Läng'sachse zum Körper des Tieres wie ein echtes gelagert ist; genauere Beobachtungen uiber das Verhalten des überzähligen Beckens während 
seiner Entwicklung und darauf begründete Experimente müssen erst noch angestellt werden, bevor diese Ursachenforschung spruchreif wird. Über die Entstehungsursachen aber des bisher beobachteten einen Falls, der von dieser Regel abweicht, bin ich imstande, bei der später folgenden Besprechung der Einzelobjekte Auskunft zu geben.

Für die dritte Feststellung des vorigen Kapitels, für den Nachweis nämlich, daß das iberzählige Becken entweder vor oder auf oder hinter der zugehörigen echten Beckenhälfte liegt, wobei dann auch die ỉberzäbligen Gliedmaßen entweder vor oder anf oder hinter der zugehörigen echten zur Entwicklung kommen, sind die Entstehungsursachen nachweisbar: Feinheiten in der Schnittführung bei der Durchtrennung der zur Regeneration verurteilten echten Beckenhälfte sind dafür verantwortlich, und zwar wird das überzählige Becken hinter die zugehörige echte Beckenhälfte verlagert, wenn der Operationsschnitt durch die betreffende echte Beckenhälfte von hinten her so weit nach vorn schräg aufsteigt, daB er an der Schwanzunterseite tief in die Muskulatur einschneidet. Wenn dagegen ein reiner Horizontalschnitt von einer unverletzten echten Beckenhälfte eine obere Kappe abtrennt, so behält diese Kappe ihre Normalstellung. auch ferner bei, wenn die entstandene Wunde nur mäßig groß geworden ist und erzengt dann also später überzählige Gliedmaßen, die a uf der zugehörigen echten liegen; ist dagegen der reine Horizontalschnitt durch die Beckenhälfte und zugehörige Körperseite sehr groß geraten und klaffend geworden, so verschieben sich die durch ihn hergestellten beiden Beckenabschnitte gegeneinander, indem der obere Kappenabschnitt nach rorn hin rückt, so daß dann später auch das überzählige Becken mit seinen Gliedmaßen vor der zugehörigen Stammbeckenhälfte und der zugehörigen Stammgliedmaße zur Ausbildung kommt.

Die verschiedene Schnittführung durch die hintere Leibeswand des Tieres hat nämlich, wie später an einem Modell bewiesen werden soll, folgenden Einfluß auf die Schwanzstellung des Tieres und diese wieder auf die Stellung der Beckenbezirksabschnitte zueinander:

Der Schnitt, welcher in rein horizontaler Richtung durch die hintere Leibeswand und die beiden Beckenbezirksanlagen des Tieres geht und dadurch das ganze Hinterende der Leibeshöhle - bis auf den schmalen oberen Saum, der den oberen Beckenbezirksabschnitt enthält - von der Schwanzunterseite loslöst, bewirkt, daß der Schwanz dadurch seine Stiitzpunkte im unteren Schwanzsaum des Tieres und 
am Hinterende der Leibeswand verliert, aus der Normalstellung ziemlich stark nach unten hinabsinkt und non den mit ihm verbunden gebliebenen oberen Beckenbezirksabschnitt vor den in der Leibeswand gebliebenen unteren schiebt. Dringt dagegen ein schräger Schnitt (Fig. 14-16ef) mehr oder weniger tief in die unteren Schwanzmuskeln des Tieres ein, so hebt sich die Schwanzspitze des Tieres und sein ganzer Schwanz verkrimmt sich nach oben und zwar deshalb, weil die Muskeln der Schwanzunterseite infolge der Durchschneidung nicht mehr imstande sind, dem Tonus der Muskeln der Schwanzoberseite Widerstand zu leisten, weshalb der Schwanz nach der Oberseite hin hoch gehoben und verbogen wird, dadurch aber wird auch der obere Beckenbezirksabschnitt des operierten Tieres hinter den unteren verschoben und dadurch kommen dann hier zum

Fig. 11.

Fig. 12.

Fig. 13.
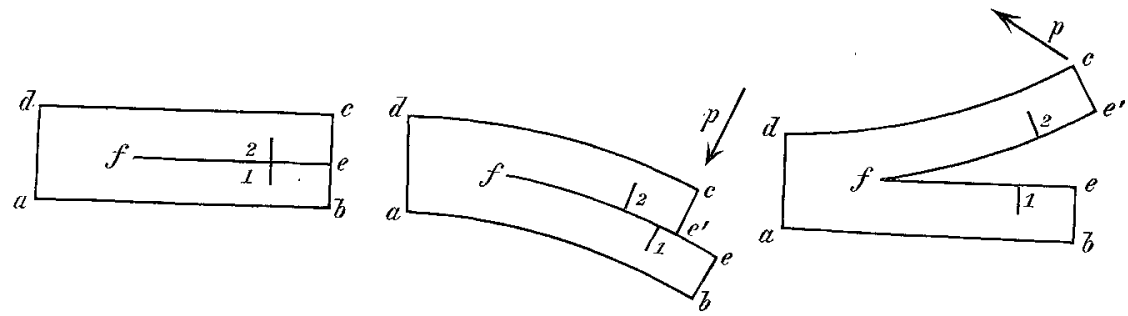

Schluß auch das überzählige Becken und die überzähligen Gliedmaßen des Tieres hinter der zugehörigen normalen zur Entwicklung. Die Ursache aber, warum das geschieht, wird am besten an folgendem Modell erklärt, das zur Nachpriufung leicht herzustellen ist: Wird ein Stück Radiergummi (Fig. 11) von Gestalt einer Sänle mit rechteckigem Querschnitt und mit der Seitenfläche $a b c d$ im Hinterende durch den Schnitt of so durchtrennt, dals gleichzeitig die auf der Schnittfläche senkrecht stehende Linie $1-2$ halbiert wird, so erhält dadurch das Gummistiick zwei voneinander unabhängige Endabschnitte $a b$ ef und $f e c d$ und die Linie 1-2 wird halbiert; die beiden Endabschnitte des Gummis aber behalten, wenn weiter nichts geschieht, dann noch ihre ursprüngliche Lage ïbereinander bei, wie auch die Teile der Linie $1-2$.

Auf die Beckenverhältnisse übertragen aber bezeichnet das Gummistück das Hinterende einer Froschlarve, das durch einem Horizontalschnitt (ef), der zugleich den Beckenbezirk derselben (1-2) 
durchtrennt, so gespalten wird, daß der Schwanz des Tieres $(f e c d)$ vom Hinterende seiner Leibeswand (abef) losgetrennt wird, wie das Fig. 14 mit denselben Buchstaben ergibt.

Drückt nun ferner am Gummistiick (wie in Fig. 12) eine Kraft $p$ das obere Endstïck $(f e b c)$ nieder, was einer Senkung des Schwanzes bei der operierten Larve gleichkommt, so wird durch das obere Gummiendstïck gleichzeitig auch das untere $(a b e f)$ niedergedrickt und beide verschieben sich dabei so aneinander, daß der untere $A b$ schnitt ïber den oberen zum Schluß ein beträchtliches Stück nach hinten hinausragt und daß ferner von den beiden Hälften der Linie 1-2 die obere Hälfte vor die untere geschoben wird. Das aber würde für die Froschlarve heißen: Wenn bei einer Froschlarve durch einen Horizontalschnitt das Hinterende der Leibeswand gespalten und dadurch der Larvensehwanz gezwungen wird, sich nach unten zu senken, so verschiebt er sich so zu dem von ihm losgelösten Teil der Leibeshöhle, daß der am Schwanz hängen gebliebene obere Beckenbezirksabschnitt des Tieres $\mathrm{ror}$ den in der Leibeshöhle zurückgebliebenen unteren verlagert wird. - Wird dagegen an dem Gummi mit geteiltem Hinterende, wie in Fig. 13, der obere Endabschnitt fecd durch die Zugkraft $p$ nach oben verbogen, so entfernt sich dieses Endstïck nicht nur nach oben hin vom unteren, sonderu es dehnt sich dabei gleichzeitig dessen Zugseite $\left(f e^{\prime}\right)$ sehr stark in die Länge aus und dadurch wird das in ibr liegende Linienende 2 vom anteren Linienende $l$ nach oben and hinten hin stark entfernt. Wird darauf gar noch versucht, an dem so behandelten Gummi den unteren Endabschnitt abef so stark nach oben zu verbiegen, dab er zum Schluß an den vorher verbogenen Gummiendabschnitt $f e^{\prime} c d$ stößt, so wird der vorher entstandene Zwischenraum zwischen 1 und 2 noch viel weiter, und 2 liegt dann extrem weit hinter 1 .

In Rücksicht auf die operierten Froschlarven aber lehrt dieser Versuch folgendes:

Werden bei einer Froschlarve durch einen schrägen Schnitt, der das Hinterende ihrer Leibeswand spaltet, auch die unteren Schwanzmuskeln des Tieres mit verletzt, dann wird der Schwanz durch den Muskeltonus seiner Oberseite stark nach oben verkrümmt und rückt der obere Beckenbezirksabschnitt von dem unteren nach hinten hin $a b$, und wenn sich dann später noch die losgetrennte hintere Leibeswand des Tieres dem Schwanze wieder nähert, um zum Schluß mit ihm zu verwachsen, so gestaltet sich die Rückwärtsverlagerung des oberen Beckenbezirksabschnitts zum Extrem. 
Die Rückwärtsverlagerung des oberen Beckenabschnitts aber kann endlich in den allerextremsten Fällen so weit gehen, daß durch sie folgende Verbildung des Tieres zustande kommt:

Der (Fig. 14) durch das Hinterende der Leibeswand $(a-c)$ und eine Beckenanlage $(1-2)$ schräg aufwärts und bis tief in die unteren Schwanzmuskeln $(d)$ gehende Schnitt $(e f)$ bewirkt zuerst, daß der hinterste Zipfel (c) der Leibeswand des Tieres mit dem Fig. 14, 15 und 16. darin hängen bleibenden oberen Beckenabschnitt (2) von dem Hauptteil der Leibeswand (a) ganz abgetrennt wird, wenn dann (wie in Fig. 15) durch die Hebung des Schwanzes dieser hinterste Leibeswandzipfel $(c)$ von dem Hauptteil der Leibeswand des Tieres $(a)$ extrem weit nach hinten abgerückt ist und der Hauptteil der Leibeswand dann sich hebt und dom Schwanz wieder näher kommt, um mit ihm zu verwachsen, dann erreicht in den extremsten Fällen (Fig. 16) die Leibeswand $(a)$ dabei ihren nach hinten verlagerten Zipfel $\langle c\rangle$ nicht mebr und verwächst deshalb $\vee$ or demselben mit dem Schwanz des Tieres $(d)$.
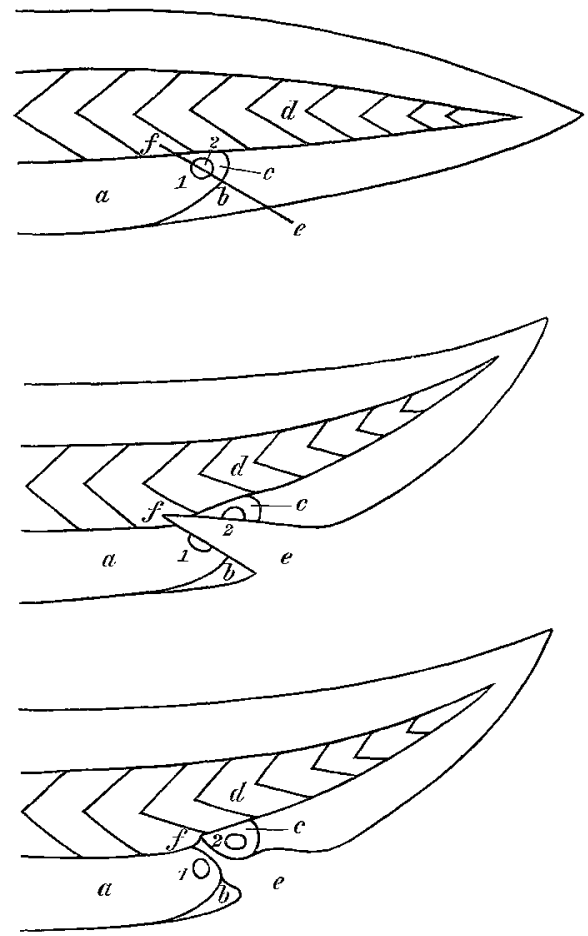
Der Zipfel $(c)$ aber regeneriert sich von seiner Wundfläche aus zu einer winzig kleinen selbständigen sekundären Leibeshöhle oder, richtiger gesagt, zu einer richtigen Hauttasche, die am Schwanz des Tieres hängt und die aus ihr herauswachsenden ibberzähligen Gliedmaßen des Tieres trägt (Fig. 45). Da aber durch diese Schnittführung auch jene Muskelverbindung für immer zerstört wird, welche im Normalzustand des Tieres zwischen dem oberen Rand der betreffenden Beckenhälfte - also dem späteren oberen Beckenabschnitt 
- und dem Kreuzbein ausgespannt ist, so muß in diesen Fällen das überzählige Becken des Tieres einen neuen Anheftungspunkt am Körper seines Trägers gewinnen und bildet sich deshalb zwischen ihm und dem Schwanzgewebe des Tieres ein anormaler Bindegewebsstrang aus, der dann auch bei dem erwachsenen Tier noch als ein starkes Band zwischen dem überzähligen Becken und Steißbein vorhanden ist.

Viertens müßte eigentlich - wie die Operationsart bedingt das ỉberzählige Becken mit seinen Gliedmaßen stets höher liegen als der zugehörige untere Beckenabschnitt, und so liegt es auch gewöhnlich; in den beiden Fällen aber, wo es nicht der Fall ist, hat die Stammhintergliedmaße der verbildeten Körperseite die überzähligen Gliedmaßen aus ibrer Erststellung ïber der zugehörigen echten Beckenhälfte hinausgeworfen, was erst im dritten Abschnitt dieser Arbeit, unmittelbar an den betreffenden Objekten, bewiesen werden soll.

Die fünfte und sechste Feststellung des vorigen Kapitels waren, daß das überzählige Becken mit seiner Querachse entweder wie das echte, d. h. horizontal liegt, oder mit derselben mehr oder weniger senkrecht gestellt ist, was mit andern Worten sagt, daß es zur Erreichung dieser letztgenannten Stellungen um seine Längsachse eine Drehung nach außen herum bis zu einem Winkel weit über 90 Grad erfahren hat (Fig. 17-20).

Die Entstehungsursache dieser Charaktere ist folgende: Wie schon früher gesagt, hat das überzählige Becken normalerweise das Bestreben, eine Stellung am Körper des Tieres einzunehmen, die der des echten Beckens entspricht, und es schickt ferner seine beiden Darmbeinflügel, die stets an der Spitze verwachsen sind, gegen den Kreuzbeinflügel der betreffenden Körperseite hin vor; demselben Kreuzbeinflügel strebt nun aber auch der echte Darmbeinflügel der betreffenden Körperseite zu und so kommt dieser sehr bald mit den gleichstrebenden Darmbeinflügeln des überzähligen Beckens in einen Kampf um den Raum. Gelingt es dann (Fig. 17) dabei dem echten Darmbeinflügel $(c l)$, das ganze überzählige Becken $\left(a^{\prime}-l^{\prime}\right)$ von seinem Platz wegrzudrängen, so behält das überzählige Becken seine bisherige, d. h. normale Orientiermg zur Körperachse auch ferner bei, ist dagegen (Fig. 18) der echte Darmbeinflugel $(c l)$ nicht imstande, das iiberzählige Becken $\left(a^{\prime}-l^{\prime}\right)$ in der Art zu beseitigen, so drickt er zuerst dessen beide Darmbeinfliigel ( $c r^{\prime}$ und $c l^{\prime}$ ) auf Kosten der Lichtung $\left(l^{\prime}\right)$, die zwischen ihnen liegt, zusammen, bis sie sich 
unter Umständen berïhren, und dreht das Stiefbecken selbst um seine Längsachse mebr oder weniger herum (Fig. 19 um 90, Fig. 20 um $180^{\circ}$, indem er den benachbarten tiberzähligen Darmbeinflügel $\left(c r^{\prime}\right)$ von oben her seitlich angreift und nach anßen driickt; in extremen Fällen verwächst drittens der

Fig. 17.

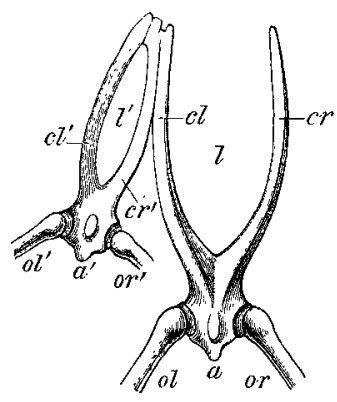

Fig. 18.

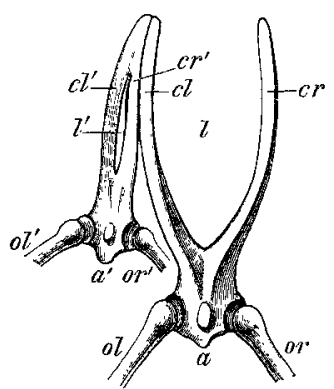
echte Darmbeinfliigel (cl) dann noch mehr oder weniger fest mit dem von ihm angegriffenen Darmbeinflügel $\left(c r^{\prime}\right)$ des iiberzähligen Beckens. ( $\mathrm{Zu}$ vergleichen sind die Abbildungen [Fig. 27 und 30] der in der Natur auf diese Weise entstandenen derartigen Beckenverbindungen.)

Bei fast allen vorliegenden Tieren zeigen siebentens die überzähligen Gliedmaßen und zuweilen sogar auch noch die mit ihnen verwachsene oder selbständig gebliebene zugehörige Stammgliedmaße mehr oder weniger große Fehlstellen oder Verbildungen, deren Entstehungsursachen nachweisbar sind, und zwar am einfachsten und klarsten an der Sammelfigur (Fig. 21), wo a den Körper der Larve bezeichnet und $d$ deren echte linke Beckenhälfte mit ihrer Gliedmaße in der Anlage, während unter $h$ der Schwanz der Larve dargestellt ist; ferner sind an der Figur dann noch unter $b, c, e, f$ und $g$ die Anlagen je eines überzähligen Beckens

Fig. 19.

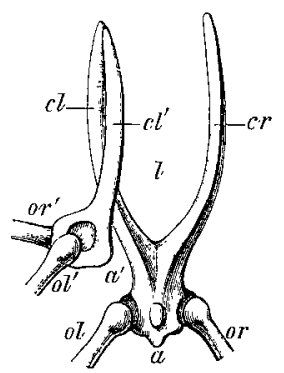

Fig. 20.

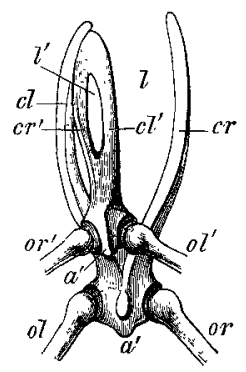
mit den zugehörigen zwei Gliedmaßen bezeichnet, die in vielen Fällen $(b, c, e)$ vollständig unabhängig voneinander sind, in den Anlagen $f$ und $g$ aber bis an die Spitzen, d. h. Zehenanlagen, miteinander verwachsen sind.

Aus dieser Figur ergibt sich dann zuerst, daß nur diejenigen überzähligen Gebilde verbildet sind, d. h. also entweder miteinander verwachsene Gliedmaßen haben oder Fehlstellen aufweisen - die in 
der Figur dunkel gehalten sind - welche hin ter der zugehörigen echten Gliedmaße und Beckenhälfte $(d)$ liegen und dem Schwanz des Tieres benachbart sind und aus der Figur ergibt sich dann auch unmittelbar, daß diese Anlagen im Kampf mit dem benachbarten Schwanz verbildet worden sein müssen und zwar zur Zeit, wenn dieser Schwanz seine Schlagbewegungen ausführte und dabei dann fortwährend gegen

Fig. 21.

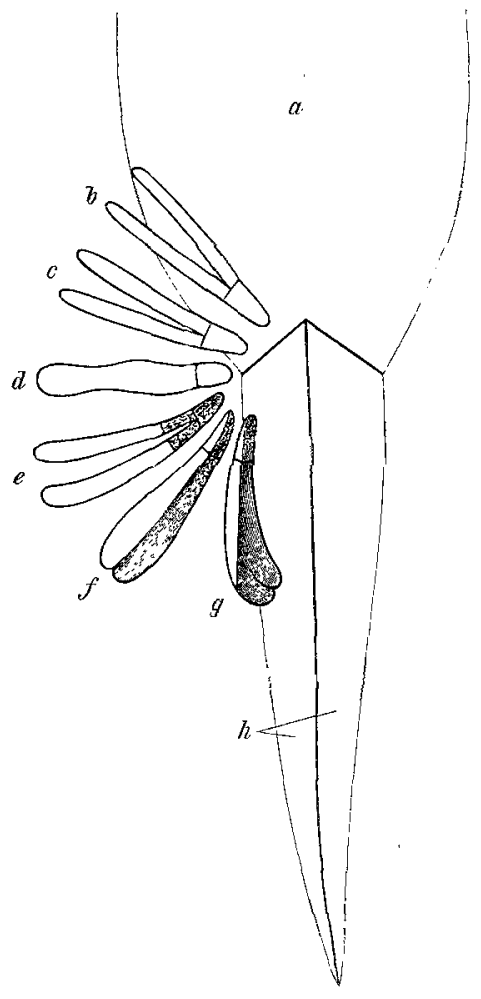
die Anlagen schlug; und das geschieht, wie später gezeigt werden soll, picht schon in der allerersten Entwicklungszeit dieser Anlagen, sondern erst dann, wenn sie eine bestimmte Entwicklungsgröße erlangt baben und sun im eigentlichen Sinne des Wortes mit dem Schwanz um den Entwicklungsraum kämpfen miissen.

Einen solchen Kampf haben mia also, wie anch die Fig. 21 ergibt, die uberzähligen Anlagen, die vor der zugehörigen echten Gliedmaße (d) liegen, natürlich wicht auszufechten und sie bilden sich daber stets normal aus, d. h. sie entwickeln ein vollständiges überzähliges Becken mit zwei zugehörigen iuberzähligen Gliedmaßen, die vollständig unabhängig voneinander siud; wenn dagegen die überzählige Anlage $(e-g)$ binter der zugehörigen normalen Gliedmaße liegt und sich dabei womöglich noch (wie $g$ ) gegen den Schwanz der Froschlarve hin entwickelt, daun kommt sie auf jeden Fall, sobald sie eine bestimmte Gröke erlangt hat, mit dem Sehwanz bei dessen Bewegungen in Konflikt und erleidet an all jenen Stellen eine Verkilimmerung, welche unter den Schwanzschlägen zu leiden haben. Wenn also (wie in $f$ ) die Aulage parallel der Schlagrichtung des Schwanzes liegt, so daß ihre ganze Innenseite durch den Schwanz angeschlagen wird, so werden bei der Anlage zuerst die entstehenden 
beiden Gliedmaßen gegeneinander gedritckt, so daß sie an den Berührungsfächen entweder mit ihrer Haut verwachsen oder bei stärkerer Druckwirkung des Schwanzes unter Verlust derselben mehr oder weniger weit und innig mit ihren Knochen; and dann verliert die Anlage später außerdem noch ihre ganze Innenseite (die in $f$ dunkel gehalten ist), und zwar in extremen Fällen so vollkommen, daß man diese verbildete Anlage für eine ursprïnglich einfach angelegte zu halten geneigt ist; in weniger extremen Fällen aber behält sie noch Reste ihrer verkitmmerten Seite und wird so zu einem ausgezeichneten Nachweisbelag.

In andern Fällen (so in $g$ ) greift dann der Schwanz nicht nur die benachbarte Seite der Mehrbildung, sondern besonders stark deren Spitze an und es kommen so zwei miteinander verwachsene tiberzählige Gliedmaßen zustande, deren Füße entweder ohne Zehen sind, oder sogar bis zu den Schaufeln verkümmert sein können.

In noch andern Fällen (so in $e$ ) und gewöhnlich dann, wenn die Anlage des Überzïlligen mit der zngehörigen Stammbildung des Tieres mehr oder weniger verwachsen ist, greift der Schwanz die Basis des Überzähligen, d. h. das überzählige Becken, aber unter Umständen anch noch die überzäbligen Oberschenkel und Unterschenkel mit an und erleiden diese dann eine Verkümmerung, die bis zum Verschwinden gehen kann.

Endlich können Schwanzschläge an den iiberzähligen Gliedmaßen starke Verbiegungen oder Brüche hervorrufen.

\section{Abschnitt III: Sonderausführungen über die Belegtiere.}

An dieser Stelle der vorliegenden Arbeit sollen nunmehr die einzelnen Knoblauchskröten besprochen werden, an denen die im Anfang der Arbeit beschriebene Operationsmethode îberzïhlige Gliedmaßen zur Entwicklung brachte. Es sind ihrer zwölf und haben folgendes:

\section{Belegling 1 (Fig. 22 und 23).}

Dieses Tier ist besonders wichtig dadurch, daß bei ihm durch den einen einzigen Schnitt, der zur Durehtrennung seiner beiden Beckenkörperhälften angewendet wurde, diese in der Tat ganz gleichartig getroffen und jede in einen oberen und unteren Abschnitt zerlegt wurden und daß alsdann keine sekundären Hemmungen die Regeneralvorgänge gestört haben, welche an dieseu Abschnitten eintraten. In- 
folgedessen erzengte hier jeder der beiden oberen Beckenabschnitte (wie das Fig. 8 schematisiert zeigt) ein ganzes uberzähliges Becken mit zwei zugehörigen Gliedmaßen, während jeder der beiden unteren Beckenabschnitte die ihm verloren gegangene obere Kappe neubildete, welche dann ihrerseits den normalen Darmbeinflügel hinzu erzeugte; dadurch erhielt dieses Tier also anßer zwei echten noch vier ïberzählige Hintergliedmaßen, im ganzen also deren sechs, und da nun

Fig. 22.

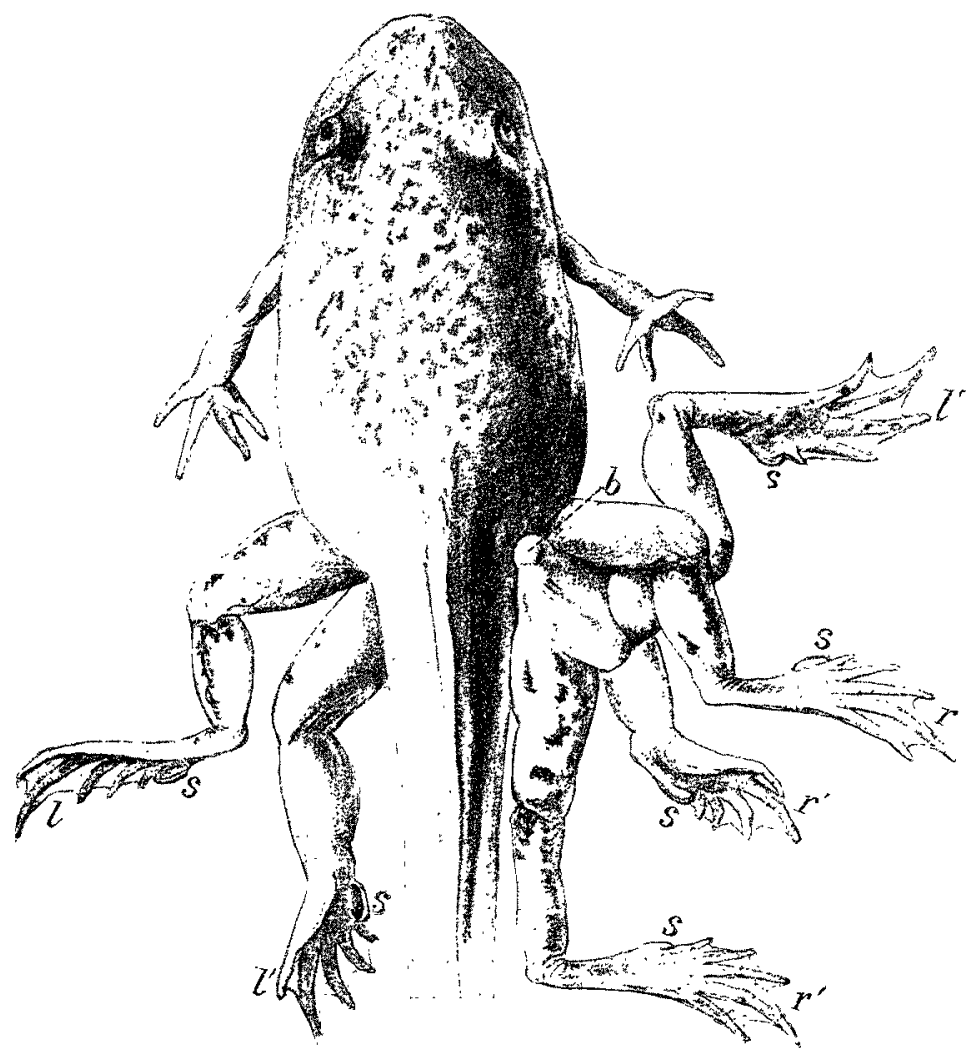

ferner bei ihm die durch den Schnitt erzeugten Beckenteilstiicke im Verlauf der Entwicklung einander gegenüber völlige Selbständigkeit behielten, so bildet dieses Belegstiick ein wirkliches Musterbeispiel für das, was durch eine derartige Operation an einem Froschhinterende überhaupt zu erreichen ist.

Wenn also an diesem Tier die Regeneralvorgänge nicht gestört worden sind, so haben bei ihm dagegen anderseits die Mehrbildungen 
nicht mehr ihre Urstellung zu den normalen Körperachsen des Tieres, sondern eine Lage, die ihnen erst im Verlauf ihrer Entwicklung durch die benachbarte normale Hintergliedmaße anfgezwungen worden ist, was in folgender Weise geschah:

Wie noch jetzt lagen im Beginn ibres Entstehens beide Mebrbildungen des Tieres mit ihren zugehörigen zwei Hintergliedmaßen

Fig. 23.

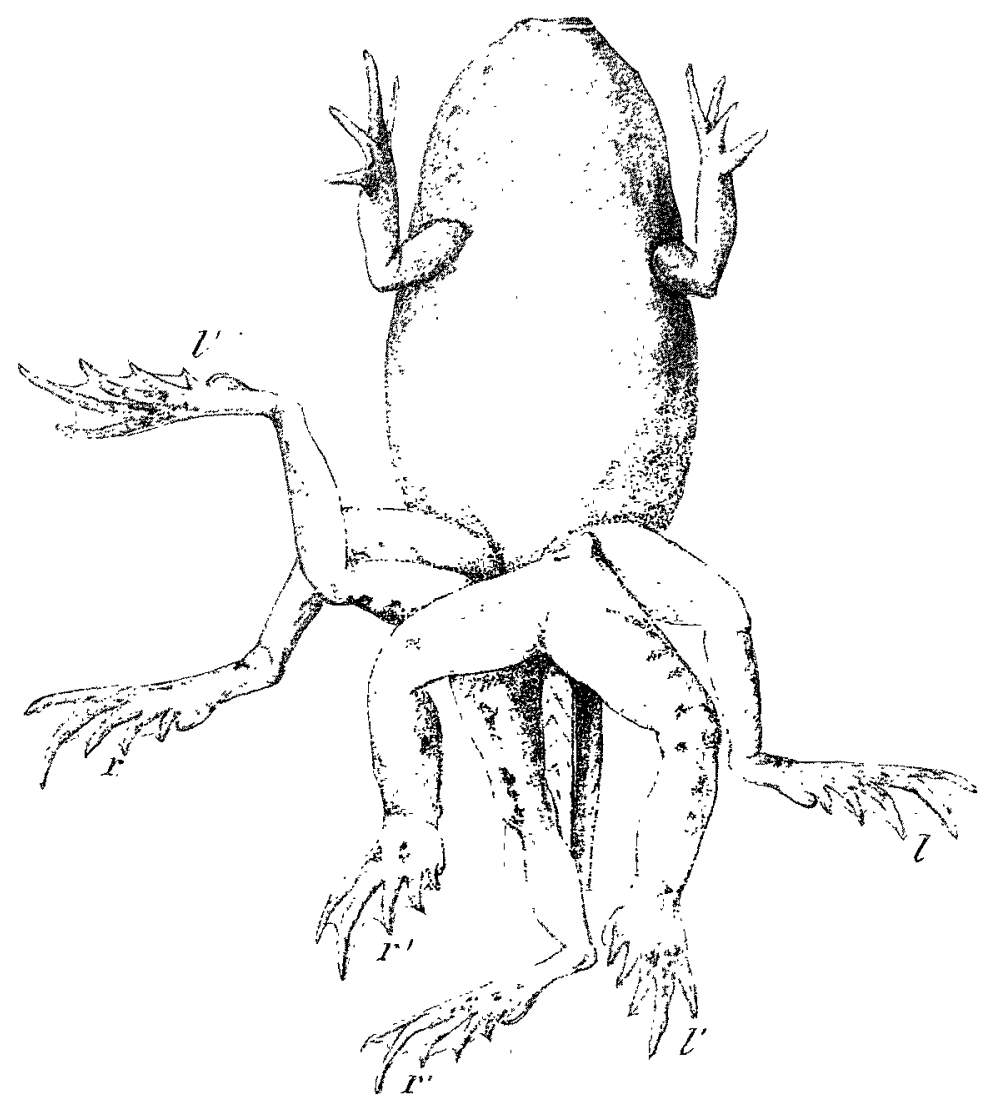

hinter der zugehörigen echten Gliedmaße und zwar zwischen ihr und der betreffenden Schwanzseite. Es hatten damn ferner beide Mehrbildungen das Bestreben, sich am Körper des Tieres wie echte derartig anzuordnen, daß ihre beiden Hintergliedmaßen in derselben Körperhorizontale nebeneinander lagen, und hatte das Tier dann also in der Normalstellung - d. h. mit dem Bauch nach unten von links nach rechts gezählt am Anfang seiner Verbildung folgende 
Gliedmaßenanordnung: echte linke Hintergliedmaße, linke überzählig, rechte uiberzählig; Schwanz; linke überzählig, rechte überzählig, rechte echt; oder in Buchstaben $l, l^{\prime}, r ; l^{\prime}, r^{\prime}, r$. So lange nun die uiberzähligen Gliedmaßen des Tieres noch klein waren und dessen echte Hintergliedmaßen noch keine Eigenbewegungen ausführten, wurde diese Urstellung der beiden Mehrbildungen des Tieres nicht angetastet, als dann aber die echten Hintergliedmaßen des Tieres bei Schwimmbewegungen nach hinten zu stoßen begannen, mußten sie an die zwischen ihnen und den Schwanz eingeklemmten Mehrbildungen oder vielmehr an die ihnen benachbarte überzählige Gliedmaße anstoßen und sie zwangen diesen dadurch allmählich eine neue Stellung zu den Körperachsen auf und zwar kam die rechte Stammhintergliedmaße (Fig. $22 r$ ) mit ihrer Mehrbildung derartig in Konflikt, daß sie von unten her an die rechte Stiefgliedmaße $\left(r^{\prime}\right)$ stieß. Dadurch wurde die ganze Mehrbildung um ihre Längsachse aus der Normalstellung auf den Rücken gedreht, so daß ihre Banchseite nunmehr nach oben schaut und ihre Gliedmaßen so gelagert sind, daß nicht mehr $r^{\prime}$ nach außen, $l^{\prime}$ dem Schwanz zugekehrt ist, sondern umgekehrt $l^{\prime}$ nach außen sieht, $r^{\prime}$ aber gegen den Schwanz. Also ist an dieser Körperseite die nunmehrige Lage der Gliedmaßen: $r, l^{\prime}, r^{\prime}$, wobei die überzähligen ihre Bauchseite nach oben kebren. Der Schwanz hat dann aber ferner durch seine Schläge nachträglich bewirkt, daß sich diese Mehrbildung an ihm gleichsam anfrichtete, so daß das überzählige Becken mit seiner Spitze $b$ nunmehr nach oben zeigt, und ferner wurde durch diese Schwanzschläge wohl auch bewirkt, daß die rechte Stammhintergliedmaße $(r)$ zum Schluß über die zu ihr hingedrehte linke überzählige $\left(l^{\prime}\right)$ hinübergriff und deren Oberschenkel beim Zuriuckgehen in ihr Kniegelenk so ungliucklich einklemmte, daß die beiden Gliedmaßen dann nicht mehr auseinander konnten, sondern im Gegenteil ihre pathologische Stellung zueinander durch Verbiegung des ïberzähligen Oberschenkels fixierten.

An der linken Körperseite des Tieres dagegen (Fig. 22) gelang es der linken Stammhintergliedmaße $(l)$ in jenen Raum zu gelangen, der zwischen der betreffenden Schwanzseite und der Mehrbildung bestand, dadurch wurde diese Mehrbildung stark nach unten gedrückt, so daß sie unter der normalen Gliedmaße und unter dem unteren Schwanzsaum zu liegen kam (wie Fig. 23 beweist), und da sie bei dieser Inanspruchnahme ferner keine Drehbewegungen erhielt, veränderte sie sonst nicht weiter ihre Stellung zu den Körperachsen des Tieres und infolgedessen liegen also auf dieser Körperseite die überzähligen 
Gliedmaßen mit ihrer Rückenseite nach oben und die rechte ist gegen den Schwanz gerichtet, die ïberzählige linke nach außen; also ist hier die Gliedmaßenfolge von links nach rechts: $l, l^{\prime}, r^{\prime}$, und bei dem Tier, wie es zurzeit vorliegt, ist demnach die Gliedmaßenstellung: $l, l^{\prime}, r^{\prime} ; r^{\prime}, l^{\prime}, r$. -

Belegling 2 (Fig. 24 und 25).

Dieser Vollfrosch, der kurz nach seiner Umwandlung in Fig. 24 von der Bauchseite aus abgebildet ist, hat auf der linken Körperseite eine Mehrbildung, bestehend aus einem überzähligen Becken

Fig. 24.

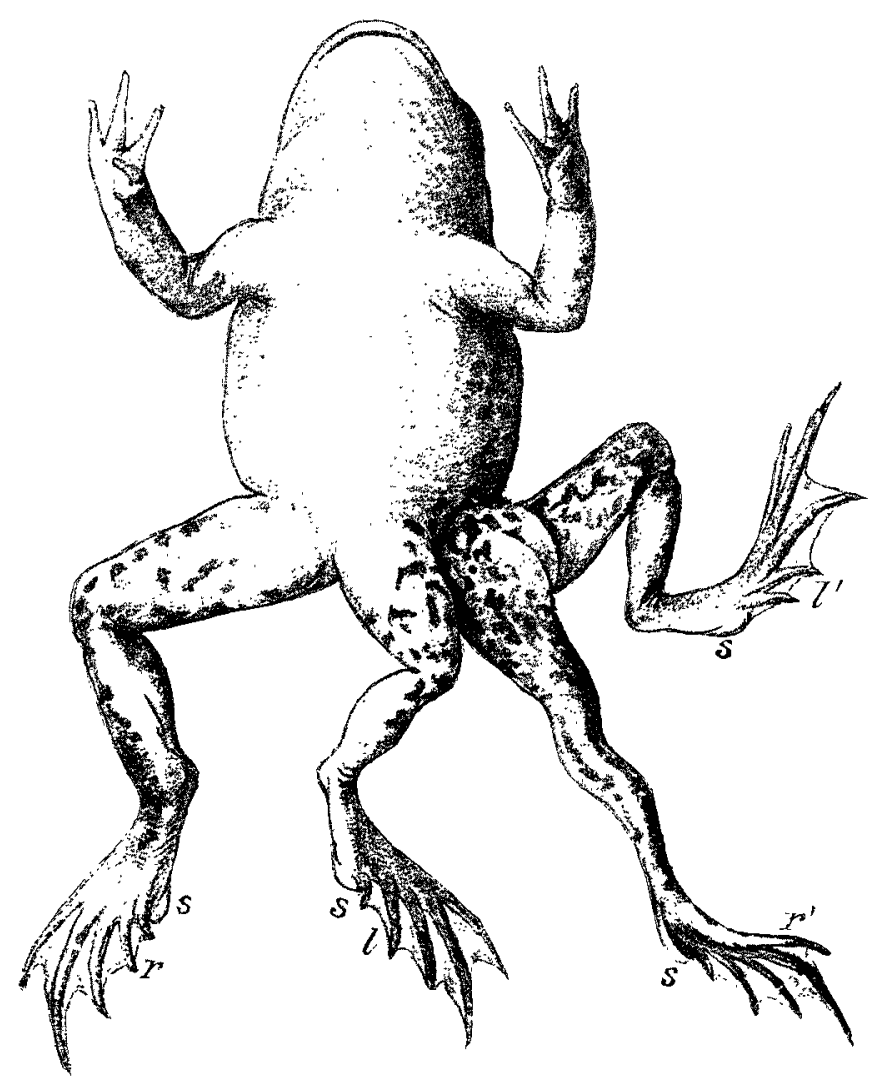

mit zugehörigen zwei Gliedmaßen, die nirgends miteinander verwachsen sind. Die Mehrbildung liegt vor der zugehörigen linken Stammhintergliedmaße und in fast reiner Normalstellung zum Körper, so daß also bei diesem Frosch von links nach rechts die Gliedmaßen 
in der Reihenfolge: $l^{\prime}, r^{\prime}, l ; r$ vorhanden sind. Dann ist hier ferner (Fig. 25) das überzählige Becken $\left(a^{\prime}, l^{\prime}\right)$ vollständig unabhängig von der zugehörigen normalen Beckenhälfte $(a, c l)$, beide gelenken ferner am linken Kreuzbeinfortsatz des Tieres und haben miteinander derart um den Raum gekämpft, daß das überzählige Becken mit seinem Körper $\left(a^{\prime}\right)$ ein wenig nach außen

Fig. 25.

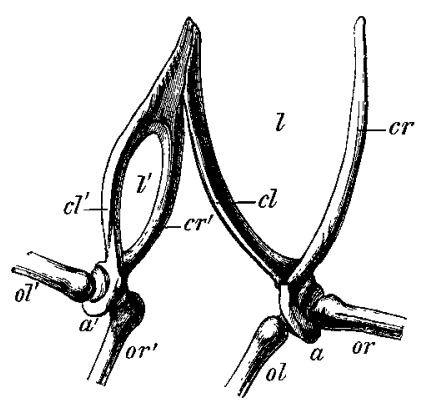
verschoben wurde and durch Druck (von $c l$ ) auf die Oberseite seines rechten Darmbeinflügels $\left(c r^{\prime}\right)$ etwas um seine Längsachse nach rechtsum rotiert worden ist.

Dann fällt an diesem Objekt (Fig. 24) beim Vergleichen seiner beiden Stammhintergliedmaßen sofort auf, daß die linke $(l)$ viel kleiner als die rechte $(r)$ ist und zwar blieb sie im Wachsen zurück, weil sie im Nährgebiet der zugehörigen Mehrbildung lag. Auch sieht man, daß die Mehrbildung die linke Stammgliedmaße aus ihrer Normalstellung gegen die Mittelebene des Tieres hin weggedriickt hat. -

Belegling 3 (Fig. 26 und 27).

Dieser kleine Vollfrosch, der wie alle nachfolgenden Artgenossen kurz nach Erlangung der Vollform abgetötet wurde, hat auf der linken Körperseite eine Mehrbildung, die aus einem überzähligen Becken mit zugehörigen zwei Hintergliedmaßen - einer rechten und linken - besteht, die gegeneinander durchaus selbständig sind, von denen aber, wie die Untersuchung ergibt, die rechte $\left\langle r^{\prime}\right\rangle$ von den Zehen an bis zum Becken hin mit der normalen linken Stammhintergliedmaße $(l)$ des Tieres verwachsen ist. Es haben demnach bei dem Tiere, sowie bei dem vorher beschriebenen, die vorhandenen vier Hintergliedmaßen die Anordnung: $l^{\prime}, r^{\prime}, l ; r$. Was freilich an der beigegebenen Abbildung erst nach einigem Nachdenken erkennbar ist, weil das überzählige Becken des Tieres, wie noch besonders gezeigt werden soll, in einem Winkel von $90^{\circ}$ so um seine Längsachse rechtsum gedreht worden ist, daß seine beiden Gliedmaßen in Wirklichkeit nicht, wie normal wäre, horizontal nebeneinander, sondern ïbereinander liegen und zwar die linke zu oberst.

Daß aber, wie angegeben wurde, bei diesem Tier die rechte 
überzählige Gliedmaße mit der echten linken verwachsen ist, lehrt. ein Blick auf die dadurch entstandene Doppelgliedmaße des Tieres (Fig. 26: $\left.l, r^{\prime}\right)$, denn deren Doppelfuß hat zwei Schaufeln $(s)$ und zehn Zehen (von denen allerdings der eine, in Beugung fixierte, in der Fußsohle nahe den beiden Schaufeln liegt), während jeder normale Fuß nur fünf Zehen und eine Schaufel hat.

Fig. 26.

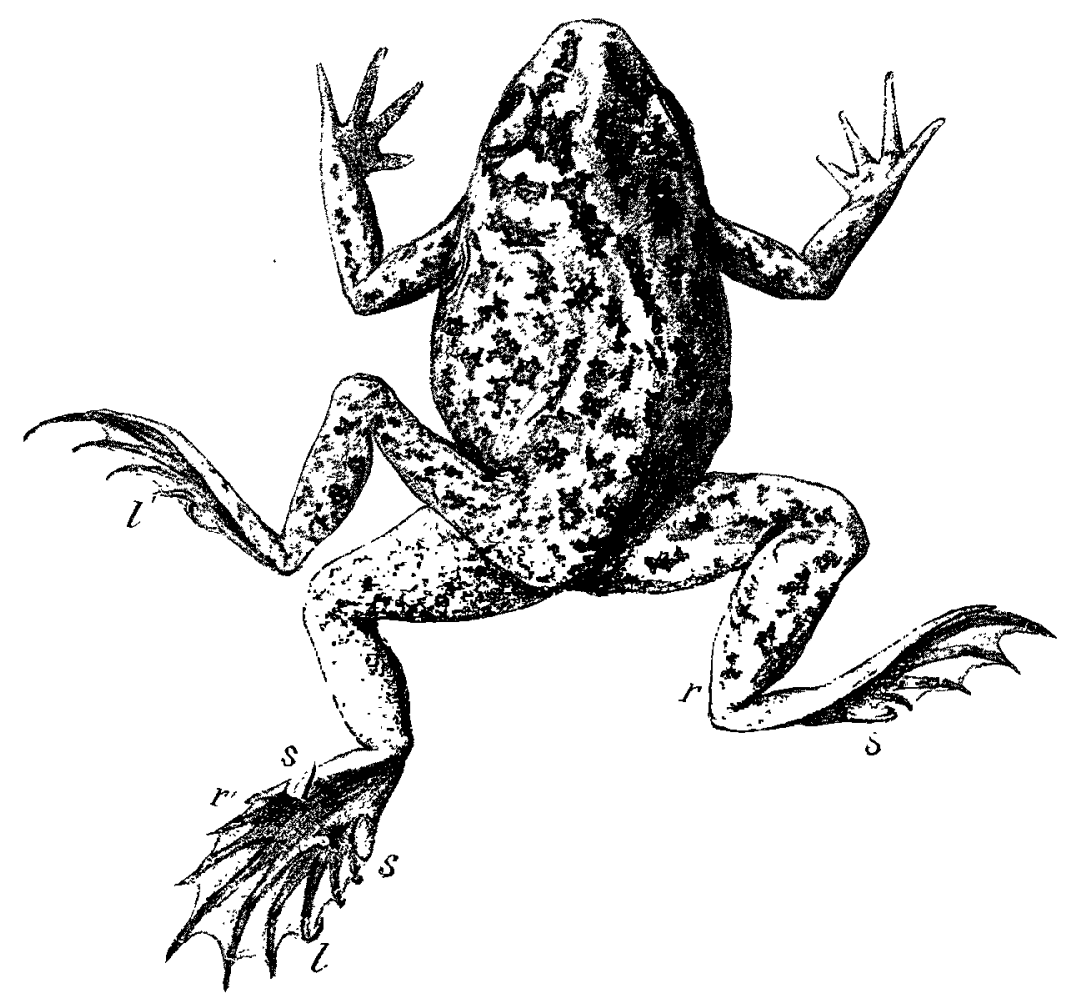

Aus der Lage der beiden Schaufeln aber, von denen jede an einem der Außenränder des Doppelfußes zu finden ist, und aus den Größenverhältnissen der Zehen des Doppelfußes ist ferner zu sehen, daß die beiden Komponenten des Doppelfußes mit ibren eigentlichen AuBenrändern verwachsen und nur spiegelbildlich einander gleich sind, worans folgt, daß der eine dieser Komponenten ein rechter, der andre ein linker HinterfuB ist.

Der aber an diesem Doppelfuß in der Mitte der Fußsohle liegende Zeh ist in Wirklichkeit der fünfte Zeh des echten (l) der 
Doppelfußkomponenten und verdankt seine Lage dem Umstand, daß die beiden Doppelfußkomponenten mit ibren Auß̂enrändern vor der Verwachsung so fest aneinander gedrückt wurden, daß sie an dieser Stelle miteinander energisch um Raum zu kämpfen hatten und der erwähnte Zeh dabei ans der Normalstellung gegen die Fußsohle hin verschoben wurde, gleichzeitig aber so viel Druck erhielt, daß er sich nur in Zwergform ausbilden konnte. Seine fixierte Beugung aber erbielt er dadurch, daß die iibrigen Zehen seines Fußes auf seine Beugesehne, die ja nur ein Ast der gemeinsamen Beugesehne des Gesamtfußes ist, durch ihr Weiterwachsen einen starken Zug ausiubten und den Zeh durch dieses Reißen an seiner Beugesehne zwangsweise in Beugung versetzten.

Im Innern der vorliegenden Doppelgliedmaße sind dann aber noch verwachsen die Fußwurzelknochen und die Unterschenkelknochen, dagegen sind die beiden Oberschenkelknochen der Doppelgliedmaße völlig selbständig zueinander und beweisen daher wieder sebr gut die Doppelnatur des Objekts, dem sie eingelagert sind.

Endlich wäre noch iuber das itberzählige Becken dieses Tieres (Fig. 27: $a^{\prime}, l^{\prime}$ ) folgendes festzustellen: Es liegt der Hauptsache nach

Fig. 27.

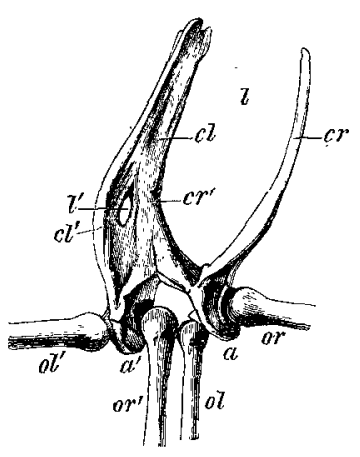
dicht angepreßt an die Außenseite der linken StammbeckenhäIfte $(a, c l)$ und mit seinem Körper $\left(a^{\prime}\right)$ ein wenig mehr kopfwärts als sie, es sind ferner seine beiden Darmbeinflïgel $\left(c r^{\prime}, c l^{\prime}\right)$ durch den linken der beuachbarten Stammbeckenhälfte $(c l)$ so sehr aneinander gedrückt worden, daß zwischen ihnen nur noch eine ganz kleine Lichtung $\left(l^{\prime}\right)$ iibrig geblieben ist. Außerdem aber wurde das ganze iiberzählige Becken, wie schon erwähnt, durch den gegen seinen rechten Darmbeinflügel $\left(c r^{\prime}\right)$ von oben her druickenden echten linken Darmbeinflügel $(c l)$ um seine Längsachse in einem Winkel von $90^{\circ}$ rechtsum gedreht, so daß nunmehr seine Querachse senkrecht steht und seine beiden Gliedmaßen nicht der Norm entsprechend in einer Horizontalebene nebeneinander liegen, sondern senkrecht übereinander.

In der beigegebenen Fig. 27 kommt die richtige Lage der beiden Becken zur Körperachse aber deshalb nicht zum Ausdruck, weil die beiden miteinander verwachsenen Becken in einer solchen Stellung gezeichnet wurden, daß die Lichtung zwischen den beiden Darmbein- 
flügeln des überzähligen Beckens $\left(l^{\prime}\right)$ zu sehen ist, was eine Abdrehung. des Beckens von der Normalstellung notwendig machte. -

Belegling 4 (Fig. 28).

Das nun zu besprechende Ther hat insgesamt fünf Gliedmaßen und ist ferner nicht anatomiseh zerlegt worden, weil es in Zukunft unbeschädigt als Belegstiick für den Wert der für diese Abhandlung

Fig. 28.

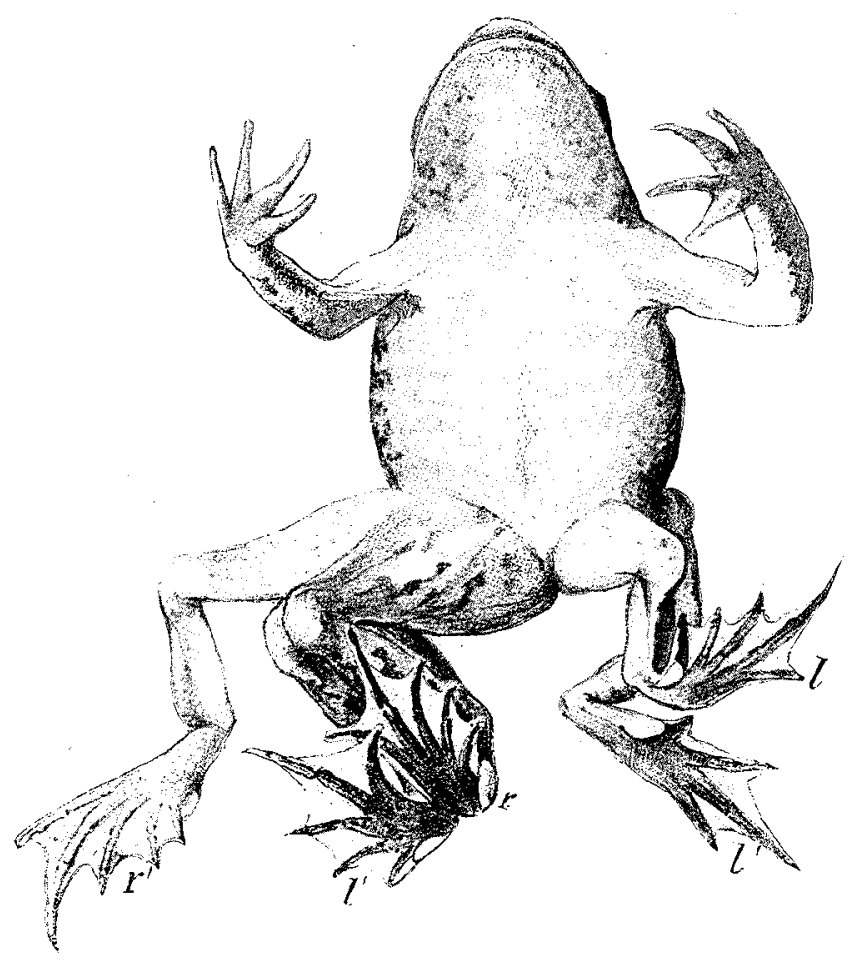

vollzogenen Operationsweise Verwendung finden soll. Es hat aber die rechte Körperseite ganz ähnlich verbildet, wie die linke Körperseite des vorher beschriebenen Tieres; denn auch hier trägt die betreffende Körperseite eine Mehrbildung, die ans einem Becken mit zwei zugehörigen Gliedmaßen besteht und auch hier ist das überzählige Becken von dem benachbarten Stammdarmbeinflugel um seine Längsachse um $90^{\circ}$. linksum gedreht worden, so daß auch hier die zwei überzähligen Gliedmaßen nicht mehr in einer Horizontalebene nebeneinander, sondern senkrecht übereinander liegen. Ferner liegen dann diese überzähligen 
Gliedmaßen etwas vor der zugehörigen normalen rechten, sind ganz selbständig gegeneinander und die linke von ihnen steckt dann allerdings erst von ihrem Untersehenkelunterende an - mit der benachbarten rechten in einer gemeinsamen Haut. In Rücksicht auf diese Verhäutelung der beiden Gliedmaßen hat also das Tier eine Art Mittelstellung zwischen dem Belegstück 2 und 3 dieser Arbeit.

Die Verbildung der rechten Körperseite des Tieres kann dagegen erst später besprochen werden; die Gliedmaßenfolge des Tieres aber ist von links nach rechts fortschreitend: $l^{\prime}, l ; r, l^{\prime}, r^{\prime}$. -

\section{Belegling 5 (Fig. 29, 30 und 31).}

Das fünfte der hier zu besprechenden Tiere schließt sich in Ruicksicht auf Wert und Lage seiner Mehrbildung dem Belegstiick 3 dieses Abschnitts unmittelbar an, geht aber insofern weit über dasselbe hinaus, als bei ihm die Mehrbildung viel stärker um ihre Beckenlängsachse rotiert worden ist. Das Tier hat also an der linken Körperseite eine Mehrbildung, die aus einem Becken mit zwei ỉberzähligen Gliedmaßen einer rechten und linken - besteht, die völlig unabhängig voneinander sind; von denen aber die rechte $\left(r^{\prime}\right)$ von den Zehen an bis zum Becken mit der normalen linken Hintergliedmaße des Tieres (l) verwachsen ist; deshalb haben auch bei diesem Tier die vorhandenen vier Hintergliedmaßen, von links nach rechts gesehen, die Auordnung: $l^{\prime}, r^{\prime}, l ; r$. $\mathrm{Daß}$ auch hier die ïberzählige rechte Hintergliedmaße $\left(r^{\prime}\right)$ mit der echten linken $(l)$ verwachsen ist, lehrt schon am Vollbild die Form des dadurch entstandenen Doppelfußes und eine Vergleichung desselben mit dem Doppelfuß des Beleglings dieser Arbeit Nr. 3 (Fig. 26). Dieser Doppelfuß hat zwei Schaufeln $(s)$ und acht Zehen, während jeder normale Fuß nur fünf Zehen und eine Schanfel hat. Aus der Lage seiner beiden Schaufeln aber, von denen jede an einem der Außenränder des Doppelfußes liegt und aus den Größenverhältnissen seiner Zehen ergibt sich ferner, daß die beiden Komponenten mit ihren wahren Außenrändern verwachsen und nur spiegelbildlich einander gleich sind, woraus folgt, daß der eine dieser Komponenten ein rechter Hinterfuß, der andre ein linker ist.

Es wurde nun aber bereits erwähnt, daß dem vorliegenden Doppelfuß zu voller Ausbildung zwei Zehen fehlen, da er nur acht statt zehn besitzt und es geht dann aus der ganzen Form des Doppelfußes und aus seinen Größenverhältnissen mit Sicherheit hervor, daß an ihm der erste und fünfte Stammzeh nicht ausgebildet sind und zwar der fünfte deshalb nicht, weil die beiden Komponenten des 
Doppelfußes beim Aneinanderstoßen ihrer Außenränder, die dann verwuchsen, so stark aufeinander drïckten, daß der vor allem stark belastete fünfte Zeh des Stammkomponenten unter der Druckwirkung. zu voller Rückbildung gebracht wurde; der erste Zeh aber ist nicht vorhanden, weil der ganze Fuß, zu dem er gehört, unter dem erwähnten Druck und Gegendruck eine so große Schwächnng seiner Entwicklungsenergie erfuhr, daß er zum Schluß nicht mehr imstande war, den

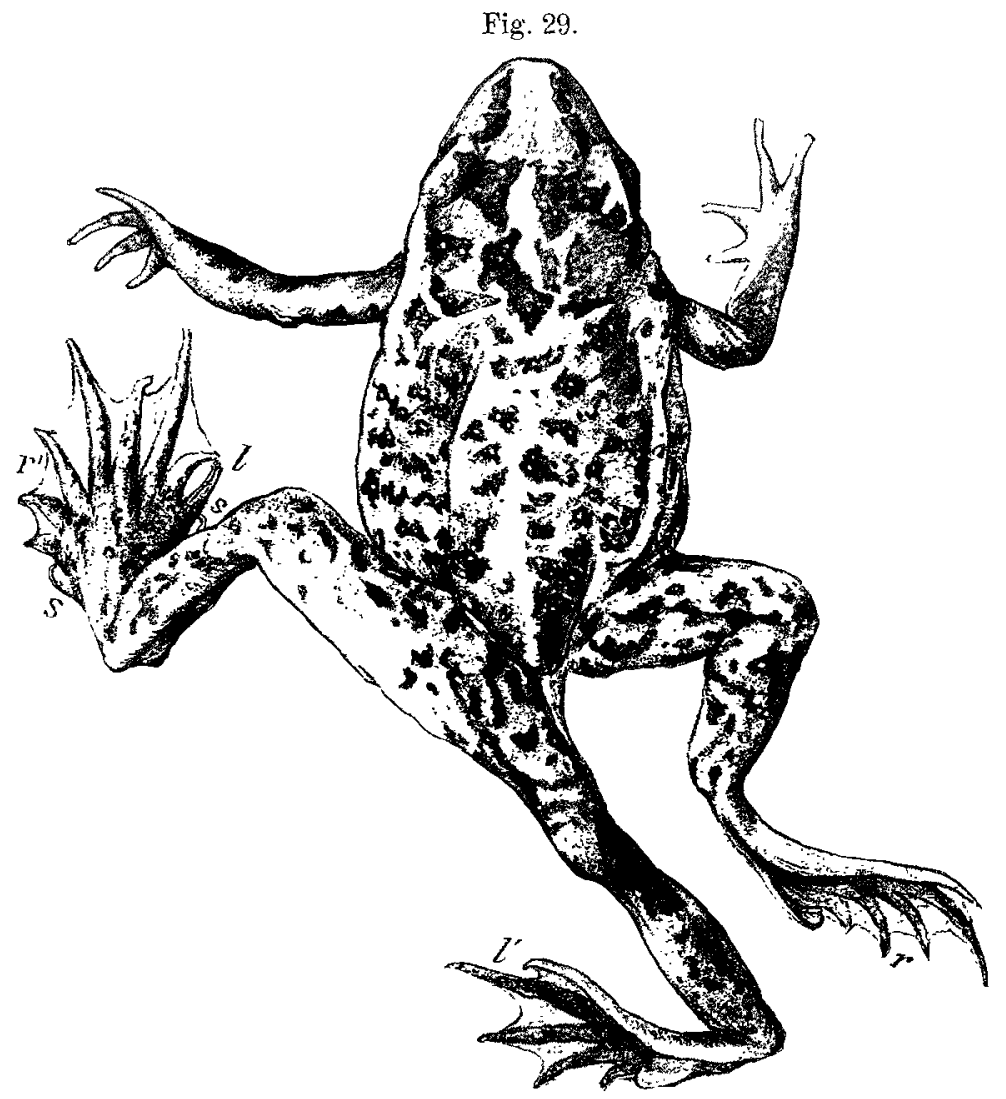

ersten Zeh, der unter all seinen Zehen zuletzt zur Entwicklung kommen mußte, noch auszubilden. - Auf Wachstumsstörungen in diesem Stammabschnitt des Doppelfußes aber weisen anch dessen zweiter und dritter Zeh hin, die unter Verkürzung der Schwimmhaut, die zwischen ihnen ausgespannt ist, gegeneinander verkrümmt angelegt sind.

Im Innern dieser Doppelgliedmaße sind dann noch verwachsen die Fußwurzeln und die Unterschenkelknochen, dagegen sind die Oberschenkelknochen derselben völlig selbständig gegeneinander und 
beweisen daher auch hier wieder sehr gut die Doppelnatur des Gebildes, dem sie eingelagert sind.

Sehr wichtig ist dann noch bei diesem Tier das Verhalten des ubberzähligen Beckens zu dem echten (Fig. 30). Es ist nämlich dieses Stiefbecken $\left(a^{\prime}, l^{\prime}\right)$ einmal viel weniger eng mit dem benachbarten echten Darmbeinflügel $(c l)$ verwachsen als bei dem Belegling 3 dieses Abschnitts und dann ist es durch diesen Darmbeinflügel um seine Längsachse nicht nur um $90^{\circ}$ rechtsläufig rotiert worden, sondern um den mächtigen Kreisbogen von $140^{\circ}$, so daß es jetzt seine Bauchseite

Fig. 30 .

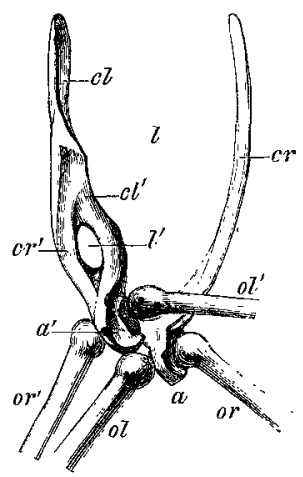

Fig. 31.

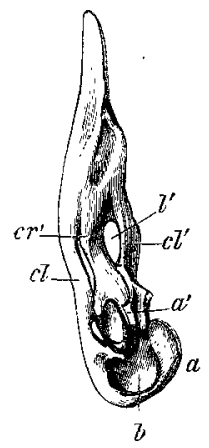
nach oben richtet und seine Rückenfläche nach der Bauchseite des Tieres hin. $\mathrm{Da}$ es mit dem benachbarten linken Stammdarmbeinflügel nicht sehr eng verwachsen ist, lehrt Fig. 31, wo es in seinem Zusammenhang mit der zugehörigen Stammbeckenhälfte abgebildet ist. Die Figur zeigt zuerst seinen Körper $\left(a^{\prime}, l^{\prime}\right)$, der senkrecht steht und an jeder Seite eine Gelenkfäche für eine der zugehörigen Hintergliedmaßen trägt; von seinem Körper verlaufen dann seine Darmbeinflügel $\left(c r^{\prime}, c l^{\prime}\right)$ und umschließen eine Lichtung $\left(l^{\prime}\right)$, die zwar klein, aber gut ausgebildet ist. Sein Körper ruht dann auf dem Körper $(\alpha)$ der Stammbeckenhälfte, deren Gelenkfläche für die linke Stammbintergliedmaße $(b)$ gut erkennbar ist; der zugehörige Stammdarmbeinflügel $(c l)$ aber geht dann neben dem rechten Stiefdarmbeinflügel $\left(c r^{\prime}\right)$ hin und ist mit demselben nur zum Teil verwachsen, nämlich derartig; daß erstens zwischen beiden zwei kleine Lichtungen übrig geblieben sind, und daß zweitens die Verwachsungsstelle der beiden Darmbeinflïgel in ihrem ganzen Verlauf gut erkennbar blieb. Aus der Ergänzungsfigur zu der eben beschriebenen aber, d. h. aus Fig. 30 dieser Arbeit, wo die eben erwähnten beiden Becken so abgebildet wurden, wie sie am Körper des Tieres liegen, ist dann des weiteren zu ersehen, in welcher Weise das Stiefbecken sonst noch Beziehungen zum echten hat; und zeigt sich aus der Figur, daB es nicht mehr, wie die bisher beschriebenen an der Außenseite des echten Beckens, sondern in der Lichtung seiner Darm- 
beinflügel $(l)$ liegt; daß es ferner mit dem echten linken Darmbeinflitgel verwachsen ist und mit demselben einen annähernd rechten Winkel bildet, was beweist - und zweitens auch aus der Stellung der daran befestigten Gliedmaßen besonders klar hervorgeht - daß es mit seiner Unterseite nach oben gerichtet ist. Das Becken selbst aber hat diese Stellung erreicht, indem es darch den echten linken Darmbeinflügel $(c l)$ so weit um seine Längsachse rechtsläufig gedreht worden ist, bis es anf dem Riicken lag; worauf erst die Verwachsung der beiden erfolgte. So auch erklärt sich nur, daß bei diesem Stiefbecken die linke Gliedmaße $\left(o l^{\prime}\right)$ nach der rechten Körperseite des Tieres gerichtet ist, die rechte $\left(o r^{\prime}\right)$ nach links, während bei dem Belegling 2 dieser Arbeit (Fig. 25) die Lage des Beckens und der daran befestigten Gliedmaßen gerade umgekehrt ist, d. h. von den Stiefgliedmaßen, die in der Horizontale nebeneinander liegen, die linke, die nach anßen gerichtete ist.

Auffüllig ist dann bei diesem Belegling endlich noch die Kleinheit des Stiefbeckens $\left(a^{\prime}, l^{\prime}\right)$ im Vergleich zum echten $(a, l)$, denn es ist, wie anch die Fig. 30 ergibt, etwa nur halb so lang, wie die mit ihm verwachsene Stammbeckenhälfte, dagegen sind die überzähligen Fiiße dieses Tieres, sowie die Unterschenkel nicht kürzer als die echten, ein Beweis also für den Satz, daß in Regeneralverlïufen die ersten Entwicklungsstufen ïberernährt, die darauf folgenden fortschreitend weniger und die letzten unterernährt werden.

Zum Schluß sei noch bemerkt: die in diesem Abschnitt beschriebenen Stiefgebilde der Beleglinge 2, 3, 5 bilden, wie leicht ersichtlich ist, in Rïcksicht auf die Drehung ihres Stiefbeckens um seine Längsachse und in Rïcksicht auf das Näherriicken desselben an die Mittelebene des Tieres eine sebr gate Stufenreihe: Bei Nr. 1 ist diese Drehung Null, das Stiefbecken liegt dem echten sehr locker an und von den Stiefgliedmaßen ist die linke nach außen gerichtet. Bei Nr. 3 dagegen beträgt die Drehung des Stiefbeckens um seine Längsachse $90^{\circ}$, es ist hier ferner das uiberzählige Becken dem echten bereits dicht angepreßt und mit ihm an den Berihhrungsstéllen verwachsen nnd seine Gliedmaßen liegen senkrecht übereinander, die linke zu oberst. Bei Nr. 4 dagegen beträgt die Beckendrehung $140^{\circ}$; es liegt das Stiefbecken hier also auf dem Stammbecken; es ist ferner dem echten dicht angepreßt und an den Berührungsstellen mit ihm verwachsen und seine Hintergliedmaßen liegen deshalb nebeneinander, aber die linke ist nach der rechten Seite des Tieres gerichtet, die rechte nach links. - 
Belegling 6 (Fig. 32 und 33).

Während die bisher besprochenen Beleglinge dieses Abschnitts in der Ausbildung ihres Überzähligen nicht wesentlich gestört wurden, zeigen die nunmehr folgenden sehr beträchtliche Störungen solcher Art, welche ohne Ausnahme aus dem Kampf um den Raum entstanden sind, den die Gliedmaßen des betreffenden Tieres, als es noch Larve war, mit seinem Schwanz auszufechten hatten. Schon der vorliegende Frosch ist ein sehr gutes Beispiel dafür, denn es

Fig. 32.

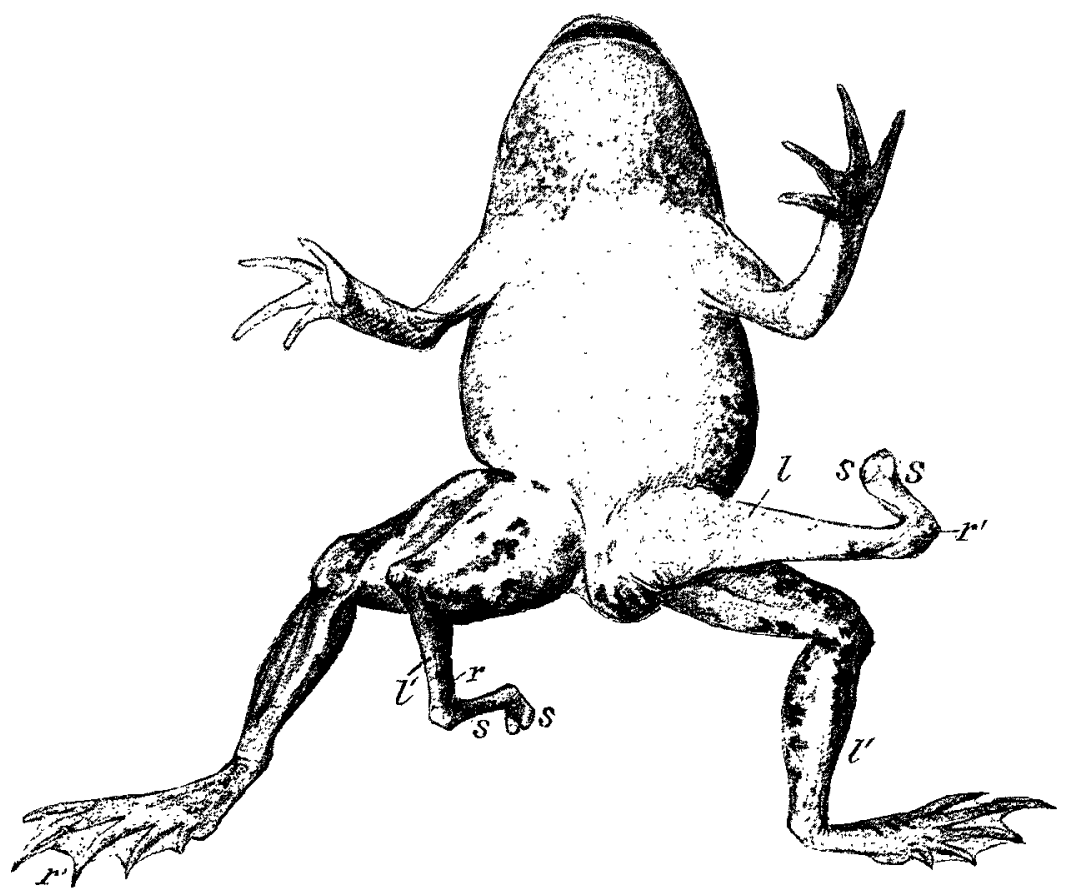

wurde bei ihm, wie sein Vollbild mit einiger Mühe erkennen läßt, seine Beckenverhältnisse aber mit Sicherheit beweisen, sechs Hintergliedmaßen angelegt, d. $h$. vier überzählige - auf jeder Körperseite zwei an einem überzähligen Becken -; von denen dann je eine mit der benachbarten echten Hintergliedmaße zu einer Doppelbildung verwuchs, so daß das Tier scheinbar nur vier Hintergliedmaßen besitzt. Seine Körperseiten wurden also bei der Operation annähernd gleich verletzt und haben deshalb auch annähernd gleiche Mehrbildungen zur Entwicklung gebracht, die dann drittens eine nahezu gleiche Lage zu den Körperachsen des Tieres haben. Aber nicht nur seine Körper- 
seiten sind annähernd gleich verbildet worden, sondern deren Mißbildungen wurden darauf in fast gleicher Weise verunstaltet, was indirekt wiederum ein neuer Beweis für die ursprüngliche Gleichwertigkeit dieser Mehrbildungen ist.

Also das Tier hat (Fig. 32) scheinbar nur vier Hintergliedmaßen, in Wirklichkeit aber sechs, und zwar außer den normalen an jeder Körperseite zwei überzählige. Der Beweis liegt in folgendem: Von den vier scheinbaren Hintergliedmaßen des Tieres sind zwei $\left(r^{\prime}, l^{\prime}\right)$ ganz unverletzt, an deren Vollausbildung wird also nicht gezweifelt werden. Die zwei andern, scheinbar einfachen Hintergliedmaßen des Tieres $\left(r, l^{\prime}\right.$ und $\left.l, r^{\prime}\right)$ sind aber stark rerbildete Doppelgliedmaßen, in denen je zwei, nur spiegelbildlich gleichartige Hintergliedmaßen vereinigt sind, also eine rechte und linke und zwar ergibt sich das auch schon äußerlich dadurch, daß jede dieser Gliedmaßen zwei Schaufeln (s) trägt, die ferner an den Außenrändern des Doppelfußes sitzen und damit beweisen, daß der Fuß, der sie trägt, wirklich ein Doppelfuß ist, der aus zwei Komponenten - einem rechten und linken - besteht; ftir das Tier ergibtsich daraus aber folgende Gliedmaßenstellung von links Fig. 33.

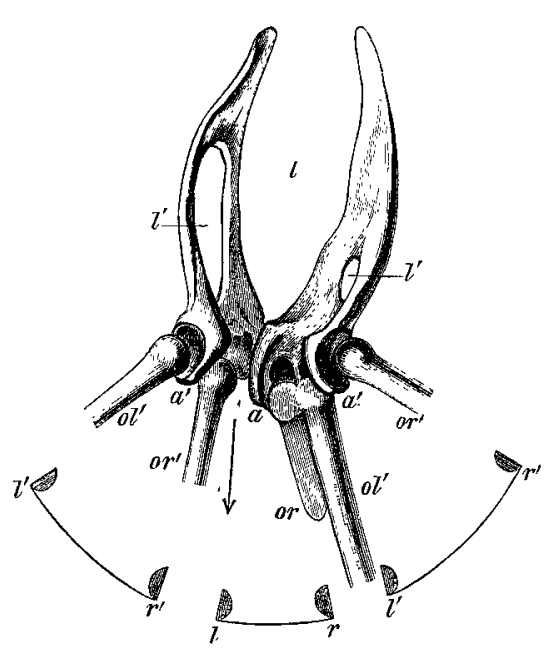
nach rechts: $l^{\prime}, r^{\prime}, l ; r, l^{\prime}, r^{\prime}$.

Noch besser und sicherer aber beweist das das Beckengebilde des Tieres, das in Fig. 33 von der Oberseite dargestellt ist. An ihm sitzen zuerst fünf Oberschenkelknochen, also mïssen dazu drei Beckenkörper gehören, die in der Tat auch gut erkeunbar vorhanden sind, dann zeigt sich ferner, daß auch die Darmbeinflügel dieses Beckenverbands zu drei Becken gehören, denn sie umfassen drei Lichtungen $\left(l, l^{\prime}, l^{\prime}\right)$, von denen die mittlere, nach oben offene $(l)$, die Lichtung des Stammbeckens ist; die beiden andern, "völlig geschlossenen $\left(l^{\prime}\right)$ zu den zwei Stiefbecken gehören, die dem Stammbecken rechts und links ansitzen. Es ergibt sich ferner aus der Fig. 33, daß diese beiden Stiefbecken, jedes durch den benachbarten echten 
Darmbeinflügel, um ihre Längsachse in einem Winkel von gnt $90^{\circ}$ rotiert worden sind, so daß bei dem Tier die zwei zusammengehörenden iiberzähligen Gliedmaßen nicht mehr nebeneinander, sondern fast iibereinander liegen und endlich ergibt diese Figur, daß nach dieser Rotation der überzähligen Becken jeder echte Darmbeinflügel mit dem benachbarten ïberzähligen, an dem er drehte, sehr eng verwachsen ist.

Die Verbildungen aber, welche den beiden Doppelgliedmaßen des vorliegenden Frosches $\left(r, l^{\prime}\right.$ und $\left.r^{\prime}, l\right)$ beigebracht wurden, sind durch Schwanzschläge des Tieres hervorgerufen worden und zwar waren die Wirkungen dieser Schwanzschläge folgende: Die beiden vom Schwanz entfernt liegenden überzähligen Hintergliedmaßen $-r^{\prime}$ der rechten Körperseite, $l^{\prime}$ der linken - haben unter den Schwanzschlägen gar nicht za leiden gehabt, und blieben daher völlig unversehrt. An beiden Doppelfüßen des Tieres dagegen fehlen die Zehen bis zu den Schaufeln (Fig. 32: s), die beiden Schaufeln selbst aber zeigen durch ihr dichtes Aneinanderliegen, daß die zugebörigen Gliedmaßen auch noch weiter gegen den Tierkörper hin in Wachsen stark geschwächt wurden. Das wird aber erst besonders klar, wenu man ihr Skelett untersucht, denn damn ergibt sich, daß in der Doppelgliedmaße der linken Körperseite $\left(l, r^{\prime}\right)$ ron den zwei Schaufeln an bis zum Becken hin nur noch die Knochen des ubberzäbligen Gliedmaßenkomponenten $\left(r^{\prime}\right)$ vorhanden sind, daß dagegen die entsprechenden Knochen der echten linken Hintergliedmaße $(l)$, d. h. also Unter- und Oberschenkel, in der Doppelgliedmaße nicht vorhanden sind, weil sie im Jugendstadium des Tieres durch Schwanzschläge zum Schwinden gebracht wurden. Ähnlich sind in der Doppelgliedmaße der rechten Körperseite des Tieres Unter- und Oberschenkel der überzähligen Komponente $\left(l^{\prime}\right)$ vollständig vorhanden, in der echten Komponente $(r)$ der Doppelgliedmaße sind sie dagegen bis auf den oberen Teil des Oberschenkelknochens verschwunden.

Auffällig sind dann noch die zahlreichen Verbiegungsstellen in den beiden Doppelgliedmaßen des Tieres; so hat die rechte einen Verbiegungsscheitel im Knie, einen zweiten in der Mitte des Unterschenkels und einen dritten in der Nähe der Fußschaufeln; bei der linken Doppelgliedmaße aber ist eine enorme Verbiegung in Unterschenkel mit Verbiegungsscheitel in der Mitte des Knochens; die Verbiegung ist dabei so stark, daß das untere Unterschenkelende an das obere anstöBt und mit ihm an der Berührungsstelle verwachsen ist. Eine Verbildung; die der beim folgenden Belegling vorhandenen und eingehend beschriebenen, ganz genau entspricht. 
Zu bemerken wäre dann noch, daß an beiden Doppelgliedmaßen dieses Tieres die ganze Hauthïlle yollständig unpigmentiert, $d . \mathrm{h}$. in ibrer Gesamtheit albinotisch ist. So stark tritt das hervor, daß diese Doppelgliedmaßen den Eindruck machen, als wären sie schon bei den lebenden Tieren enthäutet worden; die kümmerliche Entwicklung dieser Doppelgliedmaßen zeigt sich also auch schon in der Nichtausbildung ihrer Chromatophoren. -

\section{Belegling 7 (Fig. 34 und 35).}

Der vorliegende Frosch hat, im Vollbild betrachtet, vier Hintergliedmaßen, von denen außerdem zwei $\left(l^{\prime}\right.$ und $\left.r^{\prime}\right)$ von den Fußwurzeln an miteinander verwachsen sind und zwar derart, daß ihre Schaufeln $(s)$ aneinander stoßen. Es erweisen sich deshalb die verwachsenen Fiiße als zwei nur spiegelbildlich gleiche, die aber im Gegensatz zu den bisher beschriebenen mit ihren Innenrändern verwachsen sind, was, wie Versuche lehren, dann zustande kommt, wenn die zu einem und demselben Becken gehörigen zwei Hintergliedmaßen in Normalstellung bis zur Berihrung einander genähert werden. Es sind bei diesem Belegstiick also die beiden Stiefgliedmaßen $\left(l^{\prime}\right.$ und $\left.r^{\prime}\right)$ zu einer Doppelgliedmaße verwachsen, was im übrigen die Untersuchung des zugehörigen Beckens noch sicherer beweist, da sie folgendes ergibt: Des Tieres Stammbecken (Fig. 35: $a, l$ ) ist durchaus normal gestaltet und trägt die durchaus normal gestalteten beiden echten Hintergliedmaßen (or und ol) des Tieres, die deshalb auch in Fig. 34 mit $r$ und $l$ bezeichnet sind. Beim Stammbecken aber, senkrecht über dem linken Darmbeinflügel $(c l)$ steht dann noch eine überzählige Beckenhälfte $\left(c l^{\prime}\right)$ und ist sogar mit ihm eine kurze Strecke lang rerwachsen. Dieser Stiefbeckenhülfte des Tieres sitzt dann an der Außeuseite ein voll ausgebildeter Stiefoberschenkel $\left(o l^{\prime}\right)$ an, also ein linker Stiefoberschenkel, dessen unteres Ende übrigens, wie ganz genau die Untersuchung ergibt, aus zwei miteinander untrennbar verwachsenen Köpfen besteht und diese tragen dann weiter zwei Unterschenkel $\left(u r^{\prime}\right.$ und $\left.u l^{\prime}\right)$, die beide voll ausgebildet, aber auch gleichartig verbogen sind und zwar derartig derb, daß bei jedem von ihnen ein Biegungsscheitel in der Mitte liegt und die beiden Biegungsschenkel so weit aneinander geruickt worden sind, daß sie in ihrer ganzen Länge miteinander verwuchsen; dies schließt dann einmal die Möglichkeit einer Riuckbiegung der Unterschenkel ans und bewirkt, daß dieselben ihr Sprunggelenk nach oben richten. Dann trägt jeder dieser beiden Unterschenkel einen voll ausgebildeten Fuß 
und diese beiden Füße sind, wie anch ihr Knochenbau zeigt, mit ihren Innenrändern verwachsen. Also ist gar kein Zweifel, daß in dieser Doppelgliedmaße des Tieres seine beiden tuberzähligen Hintergliedmaßen stecken.

Ein Rückblick auf das Abnorme an diesen beiden verwachsenen überzähligen Hintergliedmaßen ergibt demnach folgendes: Die Füße sind von den Schaufeln an miteinander verwachsen, die beiden Unterschenkel sind ganz gewaltig verbogen und zwar derartig, daß die

Fig. 34 .

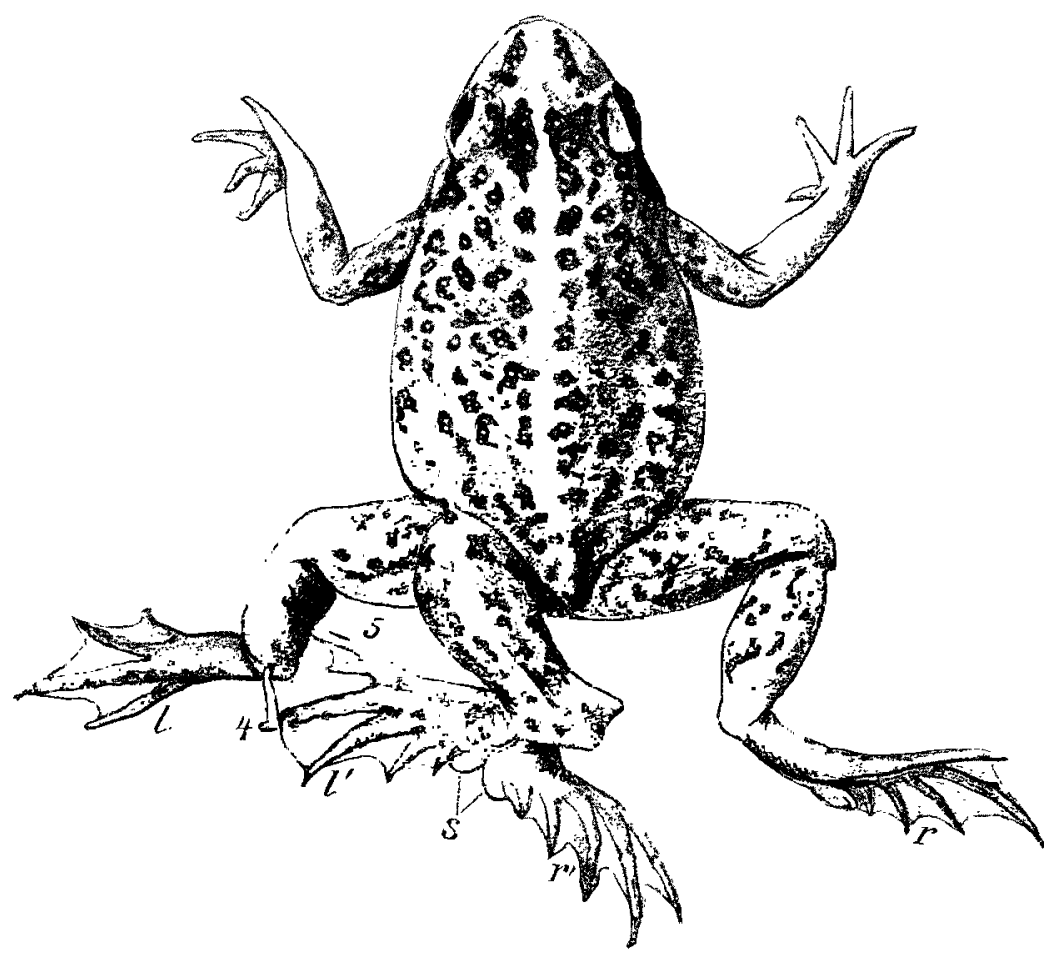

Füße dadurch von der Symmetrieebene des Tieres, der sie im ersten Teil ihrer Entwicklung zustrebten, wie Fig. 34 zeigt, weggebogen sind. Von den beiden in dieser Doppelgliedmaße ursprïnglich vorhanden gewesenen zwei Oberschenkeln fehlt der rechte (d. h. der, welcher dem Schwanz des Tieres am nächsten lag) bis auf seinen untersten Teil und ebenso fehlt am überzähligen Becken des Tieres die rechte Seite, d. h. ebenfalls diejenige, welche dem Larvenschwanz des Tieres zugewendet war. Daraus folgt, daß bei diesem Belegstück 
die Schwanzschläge zuerst die beiden Gliedmaßenanlagen des Tieres so stark gegeneinander drückten, daß diese zu einer Doppelgliedmaße verwuchsen und dann vernichteten die Schwanzschläge die ihnen benachbarte Seite des Überzähligen vom rechten Darmbeinflügel an, bis zum rechten Oberschenkelende; indem dann aber die Schwanzschläge die überzähligen Unterschenkel des Tieres bis zum äußersten verbogen, bewirkten sie, daß der Fuß der Doppelgliedmaße ihrem schädigenden Einfluß entzogen wurde und sich daher bis zum Tode des Tieres unverletzt fortbilden konnte. Interessant ist es aber, daß nach dieser Unterschenkelverbiegung anderseits der linke Stammhinterfu $\beta(l)$ bei seinen Streckbewegungen mit dem linken Stiefhinter$f u B$ des Tieres $\left(l^{\prime}\right)$ in Kampf geriet, und zwar stieb er (Fig. 34) bei jeder Fig. 35. dieser Bewegungen entweder in den Zwischenraum, der zwischen dem Zeh 4 und 5 des überzähligen Fußes (l') lag, oder an die Spitze dieser beiden Zehen. Dadurch verbog er einmal die Spitze des Zeh 4 so, daß sie nunmehr in einem rechten Winkel dem Anfangsende des Zehs aufsitzt; dann wurde zweitens durch sein Schlagen gegen die Schwimmhant, die zwischen Zeh 4 und 5 ansgespannt ist, diese Schwimmhaut zum Schwinden gebracht und endlich wurde der Zeh 5 des überzäh-

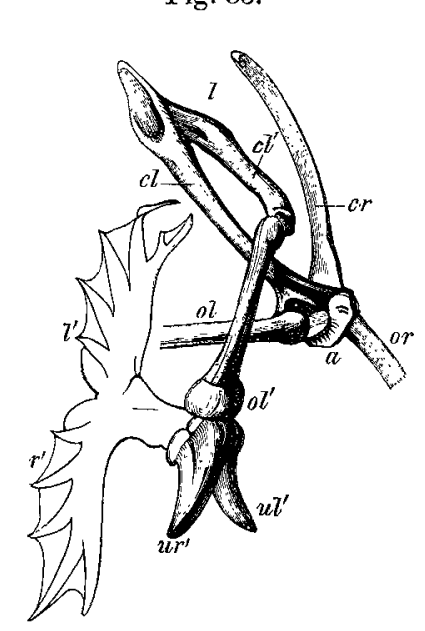
ligen Fußes $\left(l^{\prime}\right)$ durch diese Fußschläge gebrochen und sein Spitzenteil dadurch gegen den Zeh 4 hin abgelenkt; der Zeh 5 selbst aber erzeugte aus der dabei an seiner Außenseite erhaltenen Wunde eine überzählige Spitze, wodurch zugleich der Beweis erbracht ist, daß bei den Fröschen in freier Natur iiberzählige Zehenspitzen aus Wunden entstehen können, welche durch Verbiegung der Zehen angelegt werden, d. h. also: genau so wie bei allen iibrigen Landwirbeltieren.

Aber auch der Stammfuß des Tieres $(l)$, der all dieses Unheil am ibberzähligen $\left(l^{\prime}\right)$ hervorgerufen hat, kam bei diesem Kampf um den Raum nicht unbeschädigt davon; er erreichte einmal nicht die Größe des rechten Stammfußes des Tieres und dann hat er nur vier entwickelte Zehen, denn es fehlt ihm der erste, und ferner - was wich- 
tiger ist - fehlt ihm auch an seiner Innenseite die Schaufel. Es ist das aber ein. Beweis dafür, daß er gerade mit seiner Innenseite den Angriff auf die benachbarte überzählige Hintergliedmaße unternahm, was nicht Wunder nimmt, wenn man bedenkt, daß der Froschfuß während seiner Schwimmbewegungen mit seiner dem Fuß vorangehenden Vorderseite das Wasser durchschneidet. -

Belegling 8 (Fig. 36 und 37).

Dieses Tier hat, wie sein Vollbild ergibt, vier Hintergliedmaßen, also zwei überzählige. Es liegen dieselben ferner an der linken

Fig. 36.

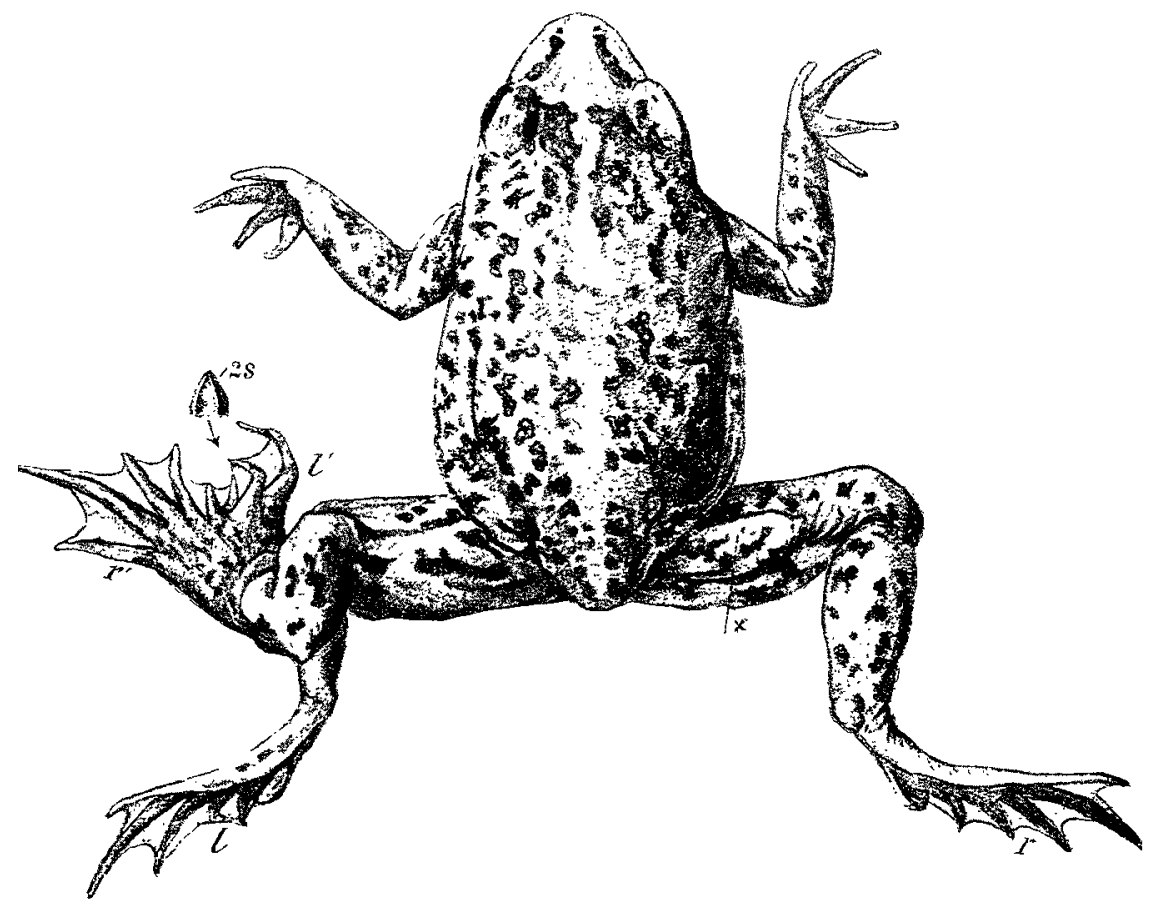

Körperseite hinter der linken Stammgliedmaße (l) und stecken in ihrem Oberschenkelbezirk mit derselben in einer gemeinsamen Hauthülle. Dabei bilden diese überzähligen Gliedmaßen von den Zehen an ein Doppelgebilde $\left(r^{\prime}, l^{\prime}\right)$, dessen Füße mit ihren Innenrändern so stark verwachsen sind, daß die beiden Fußschaufeln zu einer Doppelschaufel $(2 s)$ verschmolzen, was aus der charakteristischen Herzform dieser Doppelschaufel sicher festzastellen ist. Ferner hat von den beiden Komponenten dieses Doppelfußes nur einer und zwar der 
rechte $\left(r^{\prime}\right)$ die normale Zehenzahl, der linke $\left(l^{\prime}\right)$ dagegen nur drei Zehen, denn es fehlen ihm der fünfte und erste. Der Fuß erhielt diese Verbildung wahrscheinlich deshalb, weil er unter Einfluß von Schwanzschlägen so stark an die linke Hintergliedmaße gepreßt worden ist, daß er dadurch die Riuckbildung des fünften Zehs und eine Nichtausbildung des ersten erlitt, ähnlich wie das schon an dem früher besprochenen Tier nachgewiesen worden ist. Ferner sieht man am Oberflächenbild dieses. Tieres (Fig. 36), daß seine Doppelgliedmaße in den- Unterschenkeln sehr stark verbogen worden ist, wobei der Verbiegungsscheitel in der Mitte der Knochen liegt; also: eine Verbiegung sehr ähnlich, aber nicht ganz so stark, wie die in den Unterschenkelknochen der Doppelgliedmaße des Belegstiicks Nr. 6, und natürlich durch Schwanzschläge gegen die Doppelgliedmaße erzeugt.

Fig. 37.

Die Binnenuntersuchung des Stückes ergab dann noch folgendes (Fig. 37): Dem linken echten Darmbeinflügel des Tieres $(c l)$ sitzt, ganz nach außen geneigt, der Körper einer überzähligen linken Beckenhälfte $\left(a^{\prime}\right)$ auf. Er ist mit einer guten Gelenkfläche an der Außenseite versehen, in welcher ein linker Stiefoberschenkel $\left(o l^{\prime}\right)$ gelenkt. Dieser geht in die überzählige Doppelgliedmaße hinein und gehört zu dem liuken Komponenten derselben, dann

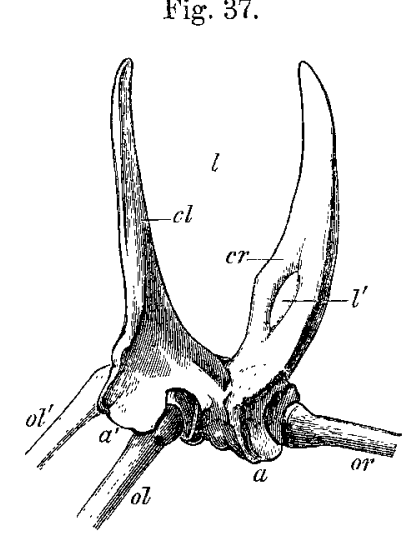
fehlen diesem überıähligen Gebilde der rechte Darmbeinflügel und Stiefoberschenkel ganz, dagegen sind sein rechter Unterschenkel und Fuß vorhanden, d. h. aber für die Entstehungsweise dieser Verbildung: Wie in allen bisher beschriebenen Fällen wurde auch hier ein ganzes tiberzähliges Becken mit zwei zugehörigen selbständigen Gliedmaßen angelegt, durch Schwanzschläge aber wurden dann die beiden Gliedmaßenanlagen so stark gegeneinander gedrickt, daß sie mit ibren Innenrändern zum Schluß untrennbar verwachsen sind; daneben aber zerstörten die Schwanzschläge die Knochenpartien des ihnen benachbarten Komponenten der Dopnelgliedmaße $\left(r^{\prime}\right)$ von der Beckenhälfte bis zum Ende des Oberschenkels, gleichzeitig aber verbogen diese Schwanzschläge die überzählige Doppelgliedmaße so sehr in den Unterschenkeln, daß zwar der Doppelfuß vor weiteren Schwanzangriffen gesichert wurde, dafür aber dessen AuBenseite mit 
der benachbarten linken Stammgliedmaße $\left(l^{\prime}\right)$ so sehr in Kampf um den Raum geriet, daß die Anßenkomponente des Fußes $\left(l^{\prime}\right)$ dadurch ihren Zeh 5 verlor und ihren Zeh 1 aus Entwicklungsschwäche nieht zur Ausbildung bringen konnte.

Wie sehr der Schwanz übrigens gerade bei diesem Tier uiber das Überzählige hinwegfegte, zeigt am besten die nur noch stehen gebliebene überzählige Beckenhälfte $\left(a^{\prime}\right)$ des Tieres, dieselbe ist, wie auch die Abbildung (Fig. 37) sehr gut zeigt, dmrch den Schwanzdruck ganz nach außen. nmgelegt worden, und auf der nach oben gerichteten Fläche geradezu glatt poliert.

Sehr wichtig ist dann noch die linke Körperseite des Tieres, denn im Vollbild bereits (Fig. 36x) zeigt sich daselbst auf dem Oberschenkel, vom Körper ausgehend, ein großer überzähliger Hautwulst. Die anatomische Untersuchung beweist dann, daß bei dem Tier auch an der rechten Körperseite eine Mehrbildung angelegt wurde, die, wie in all diesen Fällen aus einem überzähligen Becken mit zugehörigen zwei Gliedmaßen bestand, denn deren Beckenanlage ist noch zum größten Teil erhalten, da in dem scheinbar einfachen echten Darmbeinfluggel des Tieres eine Lichtung $(l)$ vorhanden ist, die beweist, daB um ihr ein echter Darmbeinflügel mit einem überzähligen Becken verwuchs, und ferner zeigt sich in dieser Abbildung, daB dieses Stiefbecken und damit die ganze zugehörige Mehrbildung um ihre Längsachse rotiert worden ist, da ihre Lichtung senkrecht auf dem echten Darmbeinflügel steht. Um so merkwürdiger ist dann, daß von der Nehrbildung sonst nichts mehr vorhanden ist, als der oben erwähnte Hautwulst anf dem rechten Stammoberschenkel des Tieres, und sind die betreffenden Teile der Mehrbildung sicher durch Schwanzschläge bis auf die beschriebenen Reste zum Schwinden gebracht worden. -

\section{Belegling 9 (Fig. 38),}

Der vorliegende Frosch ist sehr wichtig, weil er an seiner rechten Körperseite eine Verbildung trägt, welche fast als Spiegelbild jener Verbildung zu bezeichnen ist, die bei dem eben beschriebenen Tier der linken Körperseite angehört, denn auch dieser Frosch hat vier Hintergliedmaßen, darunter also zwei überzählige, die an seiner rechten Körperseite eine Doppelgliedmaße bilden, die hinter der rechten Stammgliedmaße $(r)$ des Tieres liegt und mit ihr im Oberschenkelbezirk eine gemeinsame Hülle aufweist. Demnach hat das Tier folgende Gliedmaßenstellung von links nach rechts: $l ; l^{\prime}, r^{\prime}, r$ 
Daß hier eine Doppelgliedmaße vorliegt, beweisen deren zwei deutlich getrennte Fuße, von denen der eine fünf Zehen, der andre nur vier besitzt und diese Füße sind mit ihren Innenrändern verwachsen, da ihre beiden Schaufeln in der Mitte der Unterseite des Doppelfußes eine Doppelschaufel bilden.

Sehr interessant ist dann auch, daß diese überzählige Doppelgliedmaße im Vollbild fast genau so verbildet erscheint, wie die vor ibr beschriebenen: also erstens sind ihre beiden Komponenten $\left(r^{\prime}\right.$ und $\left.l^{\prime}\right)$, die

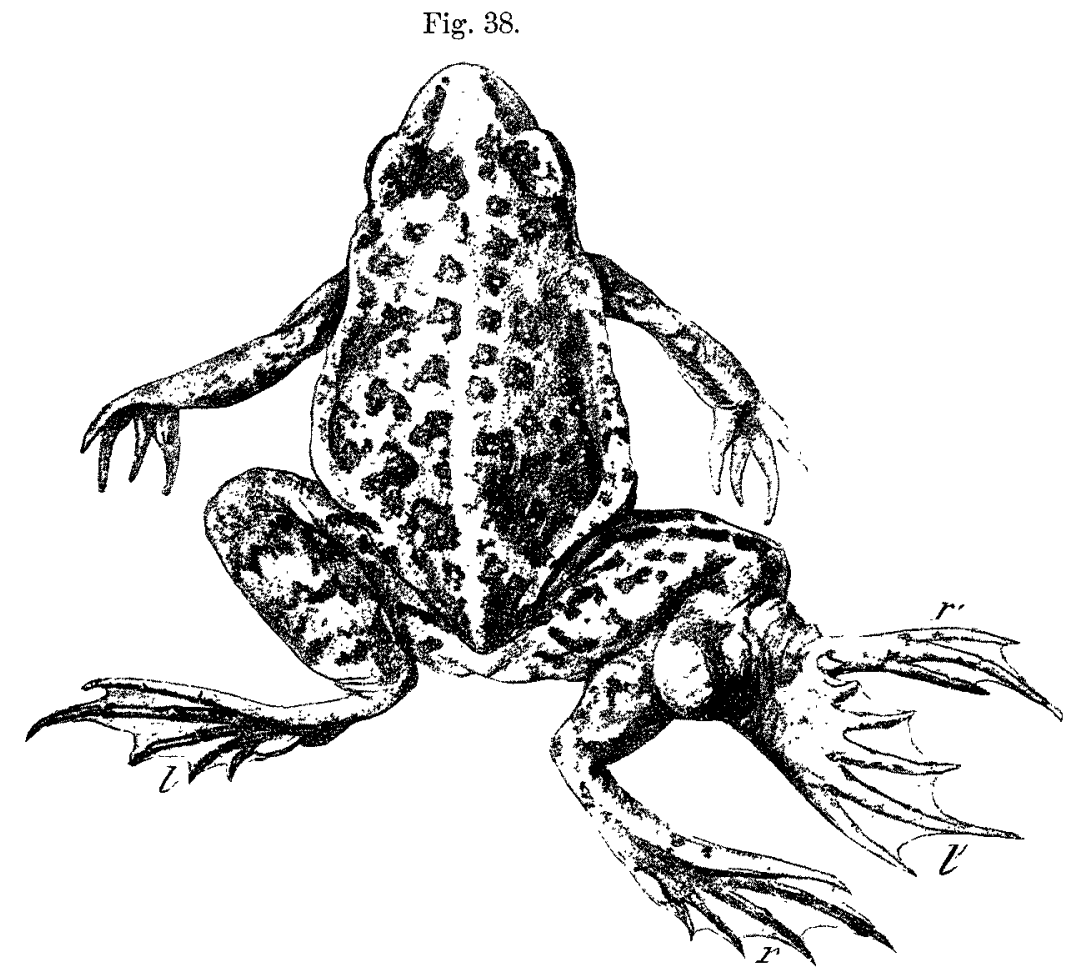

ursprünglich selbständig angelegt worden sind, durch Schwanzschläge zum Verwachsen miteinander und mit dem Oberschenkel der benachbarten Stammgliedmaße $(r)$ gebracht worden, dann sind ferner die Unterschenkel dieser Doppelgliedmaße um einen Biegungsscheitel in der Mitte der Knochen so stark verbogen worden, daß die beiden Verbiegungsschenkel jedes Knochens miteinander verwuchsen, wodurch die Zehen des Doppelfußes vor verbildenden Schwanzangriffen bewahrt blieben, dafür geriet nun aber die überzählige Komponente des Doppelfußes $\left(r^{*}\right)$ mit der benachbarten Stammgliedmaße $(r)$ in einen 
Kampf um den Raum, in welchem an ihr der Zeh 5 verloren ging und der Zeh 1 zwar noch zur Entwicklung kam, aber so tief an der Komponente, daß man fast annehmen möchte, er gehöre zu der andern Doppelfußkomponente $\left(l^{\prime}\right)$.

Es hat zu dieser Verlagerung des Zehs zweifellos ein verhältnismäßig großes Gegeneinanderdrücken der Innenränder der Fußkomponenten, bevor sie verwuchsen, sehr beigetragen; und hat hier also eine ganz ähnliche Entwicklung stattgefunden, wie sie in Fig. 26 für den gleichwertigen Zeh 5 des Tieres beschrieben worden ist. Ja dieser im Verhältnis recht starke Druck, den die Fußkomponenten beim Verwachsen ihrer Innenränder auf diese ausübten, wirkte auch auf das Verwachsen der beiden Schaufeln der Doppelgliedmaße ein, und so kam es hier nicht, wie beim eben beschriebenen Tier, zur Ausbildung einer herzförmigen Doppelschaufel, sondern einer solchen, die nur die Gestalt eines T mit sehr dünnen Schenkeln aufweist.

Im Innern der Doppelgliedmaße aber sieht es höchst seltsam ans. Das Stammbecken des Tieres ist vollständig normal gestaltet, keine Stelle desselben zeigt auch nur Ansätze zur Verbildung. Den beiden überzähligen Gliedmaßen des Tieres aber fehlen vollständig das ganze Becken und beide Oberschenkelknochen bis auf die unteren Köpfe, die zu einem einzigen Kopf untrennbar verwachsen sind. An diesem Kopf gelenken dann die beiden Unterschenkel in durchaus normaler Weise und an diesen die Füße der Doppelgliedmaße. Die beiden Unterschenkel sind dabei ebenso mächtig verbogen und haben deshalb dieselben Verbiegungscharaktere wie die der letzten drei beschriebenen Tiere.

Es ist ferner gar keine Frage, daß all diese Verbildungen an der zwischen Schwanz und rechte Hintergliedmaße des Tieres eingeklemmten Mehrbildung nur durch Schwanzschläge hervorgerufen worden sind: Der Schwanz drückte die Mehrbildung, welche als überzähliges Becken mit zwei selbständigen Gliedmaßen angelegt worden war, zuerst so zusammen, daß die Gliẹdmaßen an ihren Innenrändern miteinander verwuchsen und gleichzeitig mit dem Oberschenkel der benachbarten rechten Stammhintergliedmaße. Der Schwanz verbog dann die so entstandene Doppelgliedmaßenanlage in ihren Unterschenkeln, wodurch zwar der Doppelfuß vor Verletzungen durch Schwanzschläge bewabrt wurde, aber gleichzeitig mit der rechten Hintergliedmaße des Tieres um den Raum zu kämpfen gezwungen wurde, und dadurch an seiner überzähligen Komponente den Zeh 5 verlor und einen mangelhaften Zeh 1 entwickelte; dann aber ver- 
nichtete der Schwanz in dieser DoppelgliedmaBe die ihm zunächst liegenden Knochenpartien, d. h. das ganze tiberzählige Becken und beide Oberschenkelknochen bis auf den unteren Kopf. Weil endlich aber das überzählige Becken dieses Tieres durchaus normal gestaltet ist, ist es wohl sicher, daß das überzählige Becken dieses Tieres, wje die der meisten nunmebr noch zu besprechenden Belegstlicke dieses Abschnitts mit dem Stammbecken zu keiner Zeit verwachsen gewesen ist, sondern selbständig geblieben war und in dieser Form den Schwanzschlägen zum Opfer fiel.

Nebenbei sei noch bemerkt:

Der Umstand, daß in dieser Doppelgliedmaße von den Oberschenkeln nur noch die beiden, miteinander verwachsenen, unteren Köpfe, diese aber durchaus normal gestaltet, vorhanden sind, ist ein Beweismittel allerersten Ranges, für den Einfluß von Schwanzschlägen auf die Doppelgliedmaße. Ferner beweist der Umstand, daß bereits drei der hier besprochenen Tiere durch Schwanzschläge ganz gleichartige verbogene überzählige Unterschenkel haben, daß selbst in den Kämpfen dieser überzähligen Gliedmaßen mit dem Schwanz ihrer Träger eine gewisse Gesetzmäßigkeit liegt und diese wieder ist offenbar bedingt durch die gleichartige Schnittfuhrung durch die Leibeswand der drei Tiere. -

Belegling 10 (Fig. 39, 40 und 41).

Im Vollbild zeigt das nunmehr vorliegende Tier drei Hintergliedmaßen, mithin ist eine davon überzählig und zwar liegt dieselbe $\left(l^{\prime}\right)$ an der linken Körperseite zwischen der linken Stammhintergliedmaße des Tieres $(l)$ und seinem Steißbein $(a)$, dann aber auch über der linken Stammhintergliedmaße und unmittelbar über dem After des Frosches. Sie ist ferner im Kniegelenk halb gebeugt und schant mit der Fußsohle nach oben. In beiden Stellungen ist sie außerdem verfestigt, und zwar im Kniegelenk durch eine Scheinschwimmhaut (c) von ansehnlicher Höhe, aber von so geringer Breite, daß sie die Kniegelenkstreckung nicht erlaubt. An der ibberzähligen Gliedmaße sind ferner die Zehen nicht voneinander abspreizbar, was in der Zeichnung allerdings nicht dargestellt worden ist, weil es in ihr mehr darauf ankam, die Zehenzahl gut zu zeigen. Dann ist ferner, wie auch die Figur ergibt, des Tieres Wirbelsäule oder genauer gesprochen sein Steißbein $(a)$ etwas nach rechts verbogen. Die Gliedmaßenfolge des Tieres ist dabei $l^{\prime}, l ; r$.

Sehr interessant sind dann die Beckenverhältnisse des Tieres 
und zeigt Fig. 40 sein echtes und überzähliges Becken von der linken Seite gesehen. Daraus ergibt sich zuerst, daß das Stiefbecken $\left(a^{\prime}, c^{\prime}\right)$ dem echten $(a, c h)$ gegentiber durchaus selbständig ist. Es liegt ferner hoch über demselben und etwas mehr gegen den Schwanz hin, als das echte. Die Figur zeigt ferner, daß die zu diesem Stiefbecken gehörige überzählige linke Hintergliedmaße $\left(o l^{\prime}\right)$, wirklich der Norm entsprechend, dem Stiefbecken an der Außenseite ansitzt, woraus

Fig. 39.

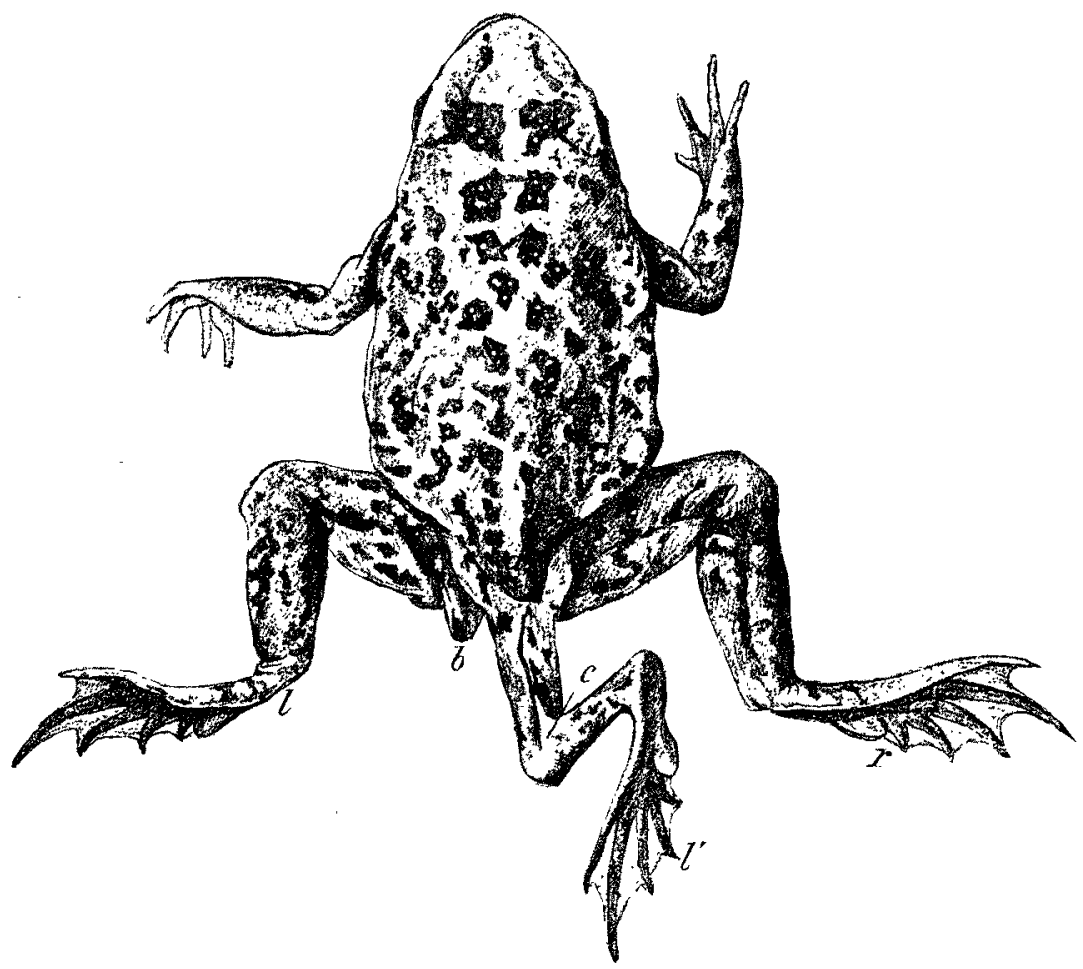

folgt, daß sie ihre derzeitige Stellung erwarb, indem sie durch den Schwanz des Tieres in ihrem Hüftgelenk derartig verrenkt wurde, daß sie um ihre Längsachse eine Kreislinie von $180^{\circ}$ beschrieb. Dann zeigt die Fig. 41 ferner, daß dieses Stiefbecken nicht, wie es den Anschein hat, eine einzige Beckenhälfte ist, denn es trägt an seiner Innenseite, die in dieser Figur abgebildet ist, noch den Rest eines Oberschenkelknochens or', und zwar in der Art verrenkt, daß sein Unterende nach der Schnanze des Tieres hinsehaut und nicht schwanzwärts, wie Norm wäre. Damit aber ist gleichzeitig bewiesen, 
daß an diesem Becken der Körper $\left(a^{\prime}\right)$ normalgemäß aus zwei Körperhälften zusammengesetzt ist und es ergibt sich weiter daraus, daß auch bei diesem Tier infolge der Operation an der linken Körperseite ein überzähliges Becken mit zwei zugehörigen Hintergliedmaßen angelegt wurde, daß aber durch die Schwanzschläge dann die ganze rechte Seite dieser Anlage bis auf wenige Reste zerstört wurde. Von diesen Resten zeigt dann der des Oberschenkels durch seine Form und Lage vor allem gut, wie energisch im übrigen diese Schwanzschläge in ihren Angriffen vorgingen.

Aber wie schon auseinandergesetzt worden ist, hatte nicht nur die rechte Hintergliedmaße $\left(o r^{\prime}\right)$ dieses ïberzähligen Beckens nnter derartigen Schwanzschlägen zu leiden, sondern auch die linke $\left(o l^{\prime}\right)$,

Fig. 40.

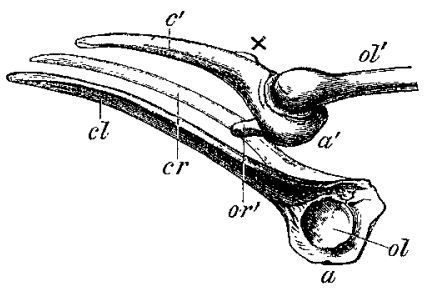

Fig. 41.

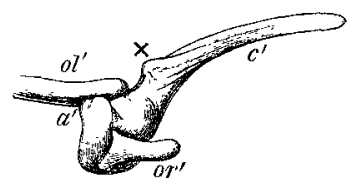

denn sie wurde einmal durch die Schwanzschläge in ihrem Kniegelenk nach der Beugeseite hin auf Daner verbogen und infolgedessen blieb an diesem Kniegelenk anch die hier vorhandene Scheinschwimmhaut erhalten, entsprechend dem Gesetz, daß Scheinschwimmhäute dann als ontogenetische Hemmungsbildnng anch bei Vollformen erhalten bleiben, wenn die Gelerke, zwischen denen sie sich ontogenetisch ansspannen, an der normalen Ausstreckung verhindert werden, oder die Glieder, zwischen denen sie liegen, nicht voll auseinanderwachsen können. Und nachdem diese Stiefgliedmaße so verbogen worden war, wurde sie noch durch den Schwanz um ihre Längsachse um $180^{\circ}$ verkreist, so daß nunmehr ibre Fußsohle nach oben schant und wird diese Verrenkung der Gliedmaße im Hïftgelenk dann auch durch eine Hautfalte (Fig. 39:b) bewiesen, welche in dem Winkelscheitel liegt, der durch die uiberzählige Hintergliedmaße $\left(l^{\prime}\right)$ mit der linken echten $(l)$ gebildet wird, und welche durch das Kreisen der überzähligen Gliedmaße im Hüftgelenk entstand.

Bei all seinen Angriffen erfuhr dann aber der Larrenschwanz 
des Frosches selbst einen so großen Widerstand, daß er an seiner Basis eine Verbiegung entgegen seiner angreifenden Schlagrichtung erfuhr, die dann auch bei der Vollform des Tieres noch in der Verbiegung des Steißbeins $(a)$ zum Ausdruck kommt.

Endlich wäre noch zu bemerken, daß bei diesem Tier die linke Stammhintergliedmaße $(l)$ kleiner als die rechte $(r)$ ist, der Entstehungsgrund dafür ist, daß sie auf dem Nährgebiet des Überzähligen liegt.

Als Nebenbemerkung mag dann noch angefiugt werden: Man könnte versucht sein, anzunehmen, daß die falsche Stellung, welche die linke überzählige Gliedmaße hier hat, durch die linke Stammhintergliedmaße des Tieres und nicht durch dessen Schwanz erzeugt worden sei, dagegen spricht aber erstens die völlig normale Ausbildung dieser linken Stammhintergliedmaße, dann zweitens die Danerverbiegung im Steißbein des Tieres und drittens ist bei diesem Frosch die überzählige Hintergliedmaße sogar so gelagert, daß sie im wesentlichen über die Symmetrieebene des Tieres nach rechts hinübergerückt ist und damit ihre Kampfstellung gegen den Schwanz deutlich verrät, denn sie konnte diese Stellung am Gesamtkörper des Tieres in Wirklichkeit nur erlangen, indem sie den Larvenschwanz energisch nach rechts hin verbog. -

Belegling 11 (Fig. 42, 43 und 44).

Das vorliegende Tier hat, im Vollbild betrachtet, an der linken Körperseite drei Mintergliedmaßen, von denen also die eine überzählig ist. Dieselbe liegt über der zugehörigen linken Stammhintergliedmaße $(l)$ und ist eine linke $\left(l^{\prime}\right)$ mit annähernd normaler Lage am Körper; ihre Beweglichkeit aber ist sehr gering. Sonst ergibt das Vollbild des Tieres nur noch, daß seine linke Stammhintergliedmaße $(l)$ wesentlich kleiner als die rechte $(r)$ ist und anch die überzählige $\left(l^{\prime}\right)$ ist entschieden etwas kleiner als die stammrechte $(r)$ oder wenigstens etwas diinner.

Die anatomische Untersuchung ergab dann noch folgendes: Das Stammbecken des Tieres (Fig. 43: $a, l$ ) ist von durchans normaler Gestalt, das iuberzählige $\left(c l^{\prime}\right)$ liegt hoch über ihm, ist aber mit seiner Darmbeinflügelspitze $\left(a^{\prime}, l^{\prime}\right)$ unter dem Kreuzbeinflügel des Tieres mit dem linken Stammdarmbeinflügel $(c l)$ verwachsen. Das ibberzählige Becken hat ferner an seiner Außenseite eine Gelenkfläche, in welcher die überzählige Gliedmaße des Tieres $\left\langle o l^{\prime}\right\rangle$ gelenkt, woraus folgt, daß dieselbe auch ans inneranatomischen Gründen eine linke ist. Dagegen 
fehlt an diesem überzähligen Becken die ganze rechte Hälfte und mit ihr zugleich auch die ganze rechte Stiefgliedmaße des Tieres, beide sind offenbar durch Schwanzschläge vernichtet worden; das ergibt sich uibrigens auch noch, wenn man das Stiefbecken von seiner rechten Seite betrachtet (Fig. 44), und dort den zerrissenen oberen Rand des ganzen Beckenkörpers sieht. Es haben hier also die Schwanzschläge die ganze, ihnen zugewandte rechte Seite der voll

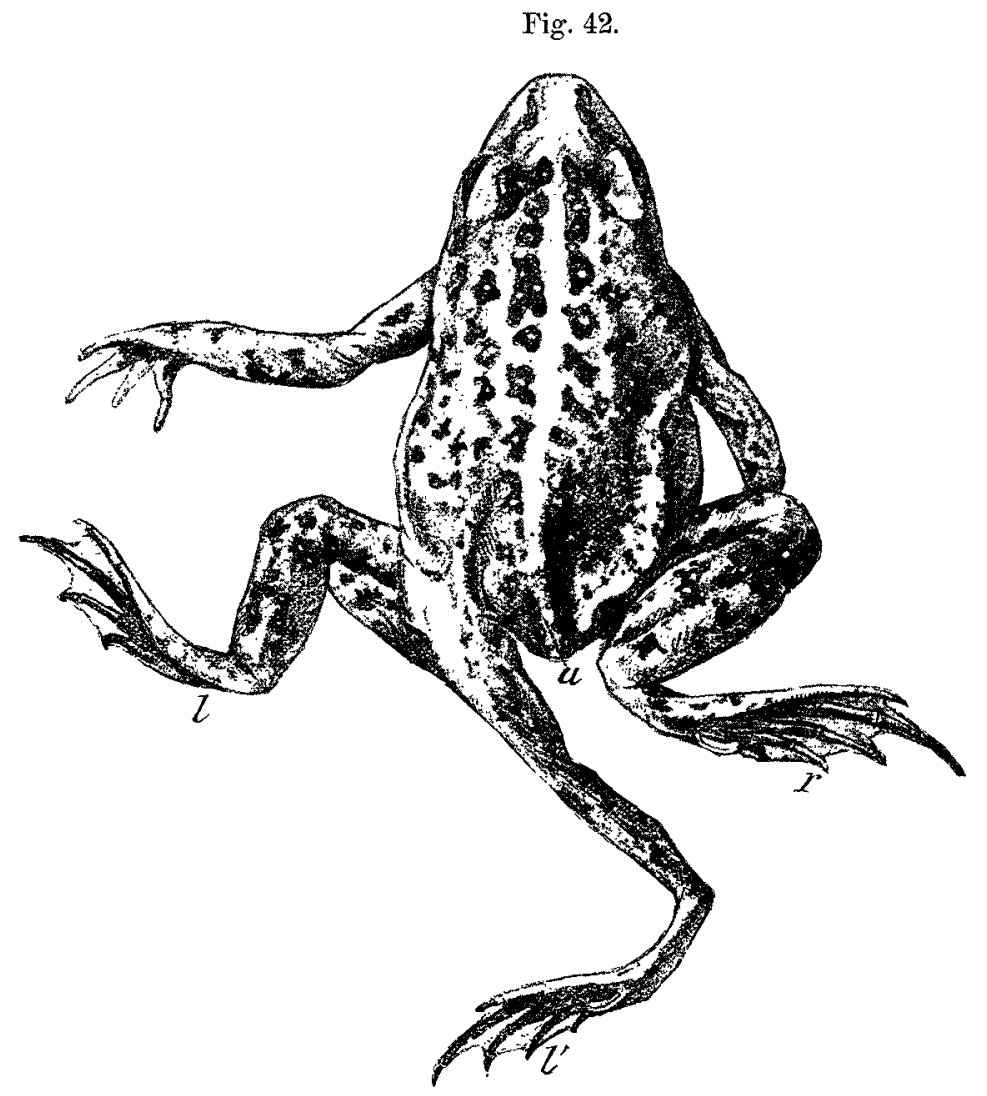

angelegten überzähligen Gebilde vernichtet und dabei wurde danı der Schwanz seinerseits an der Wurzel verbogen, was am vorliegenden Tier (Fig. 42:a) an der Dauerverbiegung des Schwanzstiels noch zu erkennen ist.

Nebenbei sei dann noch auf die große Ähnlichkeit hingewiesen, welche das hier vorliegende Stiefbecken mit dem des Frosches Nr. 9 (Fig. 35) besitzt. 
Dann fällt an diesem Stiefbecken (Fig. $43 x$ ) ebenso wie an dem des vorangehenden Tieres (Fig. $40 x$ ) ein Wulst auf, der aus der oberen Randlinie des überzähligen Beckens kurz hinter dem Beckenkörper hervorragt. Mir macht es fast den Eindruck, als wären bei diesen Tieren durch Schwanzschläge die beiden überzähligen Becken mit dieser Stelle als Scheitel stark verbogen oder gar gebrochen worden, wodurch das Profil der Becken dann diese bucklige Form erhalten habe.

Fig. 43.

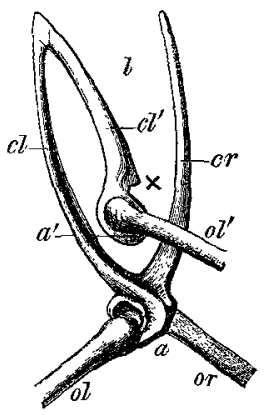

Fig. 44.

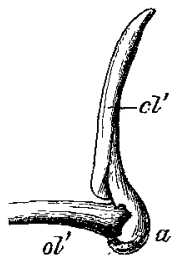

Es mag aber dahingestellt bleiben, ob es wirklich der Fall gewesen ist. Mit dem Kampf der überzähligen Becken gegen den Schwanz hat diese Buckelbildung in ihnen aber zweifellos etwas zu tun. -

Belegling 12 (Fig. 45 and 46 ).

Bei dem letzten der in diesem Abschnitt zu besprechenden Frösche sind drei Hintergliedmaßen vorhanden; eine davon also ist iiberzäblig und liegt $\left(l^{\prime}\right)$, wie unschwer zu erkennen ist, an der linken Körperseite des Tieres. Sie ist ferner ihrer Form nach eine linke, welche in einer Hauttasche derartig entspringt, daß sie an einem dünnen Hautstiel am Körper des Tieres hin und her schlottert. Sie ist ferner nicht wesentlich kürzer als die zugehörige linke Stammhintergliedmaße des Frosches, hinter der sie liegt, aber viel schlanker; sie hat ferner fünf Zehen von normaler Gestalt, die aber in Dauerbengung stehen und um den vierten dieser Zehen als Knickachse in verfestigter Greifstellung so gegeneinander gestellt sind, daß sie nicht auseinander gespreizt werden können und die Spitze des fünften die des ersten fast berührt. Dann ist der linke Stammhinterfuß dieses Tieres $(l)$ kleiner als der rechte $(r)$ und die ganze linke Stammhintergliedmaße überhaupt schwächer gebaut als die rechte, 
Fig. 45 .

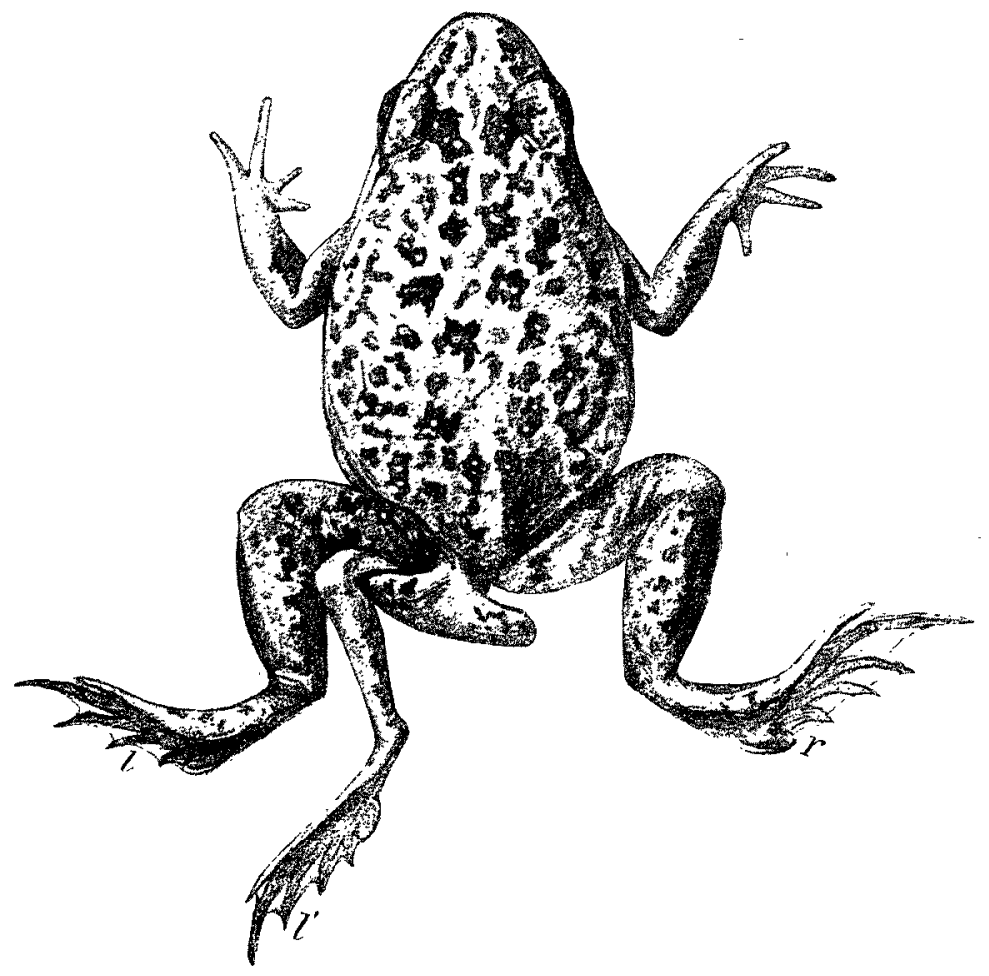

ein Beweis dafiur, daß auch diese überzählige Gliedmaße - durch Nährstoffentnahme aus ihrer Nachbarschaft - ein Wachstumshemmgebiet um sich ausFig. 46. bildete.

Die Untersuchung des Skeletts (Fig. 46) ergab dann folgendes: Das Stammbecken des Tieres $(a-b)$ erscheint rollkommen normal; es ist ihm also die im Embryonalleben abgeschnittene Kappe nachgewachsen und hat dann den zugehörigen Darmbeinflügel erzeugt. Das Skelett der überzähligen Gliedmaße, vom Oberschenkel an bis zu den Zehenspitzen, ist normal, aber der Oberschenkel (ol') trägt als Aufsatz auf sei-

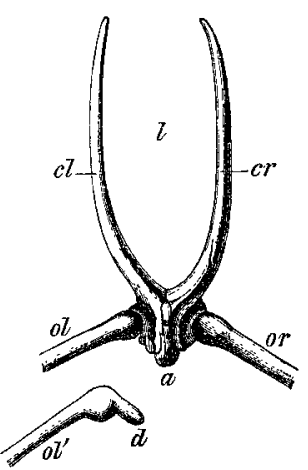
nem oberen Kopf eine kleine zungenartige Knorpelplatte $(d)$. Diese Knorpelplatte stelltzweifellos ein Stück Becken vor und man könnte einfach annehmen, sie sei jener Abschnitt vom 
Stammbecken des Tieres, der die mit ihm noch vereinigte Stiefgliedmaße erzengt habe; aber dieser Schluß wäre sicher falsch, denn dieses Knorpelstiick ist zweifellos nur ein winziger Rest eines auch bei diesen Tieren nach der Operation angelegten ganzen überzähligen Beckens, dessen rechte Hälfte aber samt der ansitzenden zugehörigen rechten Stiefgliedmaße durch Schwanzschläge des Tieres zum Schwinden gebracht wurde.

Zum Schluß noch folgendes: Da die bei diesem Tier vorhandene Mehrbildung in einer Art Hauttasehe ganz hinten am Körper des Tieres hängt, nähert sich dieser Frosch auffällig dem in dieser Arbeit als Belegling 1 beschriebenen, wo auch die beiden Mehrbildungen des Tieres mit winzigen Becken in ganz ähnlichen Hauttaschen hinter den Stammgliedmaßen des Tieres an dünnen Stielen anfgehängt sind, doch sind bei dem Belegstiuck 1 in jeder Mehrbildung noch beide Stiefgliedmaßen vorhanden, weil diese überzähligen Gebilde nach der Operation unmittelbar am Schwanz des Tieres Halt fanden und beim Größerwerden so glücklich verlagert wurden, daß sie zu keiner Zeit ihrer Entwicklung mit dem Schwanz oder den Stammhintergliedmaßen ihres Besitzers um Raum zu kämpfen hatten. 